\title{
The nucleus measures shape changes for cellular proprioception to control dynamic cell behavior
}

Authors: Valeria Venturini ${ }^{1,2}$, Fabio Pezzano ${ }^{2}$, Frederic Català Castro ${ }^{1}$, Hanna-Maria Häkkinen $^{2}$, Senda Jiménez-Delgado ${ }^{2}$, Mariona Colomer-Rosell ${ }^{1}$, Monica Marro ${ }^{1}$, Queralt Tolosa-Ramon ${ }^{2}$, Sonia Paz-López ${ }^{3}$, Miguel A. Valverde ${ }^{3}$, Julian Weghuber ${ }^{4}$, Pablo LozaAlvarez $^{1}$, Michael Krieg ${ }^{1}$, Stefan Wieser ${ }^{1, *}$, Verena Ruprecht ${ }^{2,5, *}$

${ }^{1}$ ICFO - Institut de Ciencies Fotoniques, The Barcelona Institute of Science and Technology,

${ }^{2}$ Centre for Genomic Regulation (CRG), The Barcelona Institute of Science and Technology, 08003 Barcelona, Spain

${ }^{3}$ Laboratory of Molecular Physiology, Department of Experimental and Health

Sciences, Universitat Pompeu Fabra (UPF) Barcelona, Spain

${ }^{4}$ University of Applied Sciences Upper Austria, Stelzhamerstraße 23, Wels 4600, Austria

${ }^{5}$ Universitat Pompeu Fabra (UPF), Barcelona, Spain

* Correspondence to stefan.wieser@icfo.eu and verena.ruprecht@crg.eu

Abstract: The physical microenvironment regulates cell behavior during tissue development and homeostasis. How single cells decode information about their geometrical shape under mechanical stress and physical space constraints within tissues remains largely unknown. Here we show that the nucleus, the biggest cellular organelle, functions as an elastic deformation gauge that enables cells to measure cell shape deformations. Inner nuclear membrane unfolding upon nucleus stretching provides physical information on cellular shape changes and adaptively activates a calcium-dependent mechano-transduction pathway, controlling actomyosin contractility and migration plasticity. Our data support that the nucleus establishes a functional module for cellular proprioception that enables cells to sense shape variations for adapting cellular behavior to their microenvironment.

One Sentence Summary: The nucleus functions as an active deformation sensor that enables cells to adapt their behavior to the tissue microenvironment.

Short Title: The nucleus is a cellular mechano-controller

\section{Main Text:}

\section{Introduction}

The 3D shape of an organism is built by active force-generating processes at the cellular level and the spatio-temporal coordination of morphodynamic cell behavior. Contractility of the actomyosin cell cortex represents a major cellular force production mechanism underlying cellular shape change (1), cell polarization (2) and active cell migration dynamics (3). Contractility levels are 
regulated by the activity of non-muscle myosin II motor proteins (4) and are precisely controlled to tune single cell and tissue morphodynamics during development $(5,6)$ and tissue homeostasis and disease in the adult organism $(7,8)$. Still, mechanisms that regulate the set point level of cortical contractility on the single cell level remain poorly understood.

To adjust cortical contractility levels, cells need to make quantitative measures of their mechanochemical 3D tissue microenvironment and translate this information into a defined morphodynamic output response. During embryogenesis, morphogens that act as chemical information carriers have attracted major attention (9), modulating cytoskeletal and cellular dynamics via receptor signaling pathways that tune protein activities (such as phosphorylation states) and/or protein expression levels. In contrast, physical parameters of the 3D tissue niche and mechanical forces gain importance as regulators of cellular morphodynamics and myosin IIdependent cortical contractility levels $(10,11)$. In vivo, mechanical cell deformation and cellular packing density in crowded tissue regions has been shown to influence major morphodynamic processes such as cortical actomyosin contractility $(12,13)$, cell division (14-17), cell extrusion and invasion (18). Ex vivo studies further provided evidence on the single-cell level that physical cell deformation is sufficient to modulate cortical myosin II localization and motor protein activity $(19,20)$ and influence morphodynamic cell behavior $(21,22)$.

A recent example has been the identification of a fast amoeboid migration mode, termed stablebleb migration, that is triggered by an increase in cortical contractility via genetic or physical cell perturbation (23). This morphodynamic migration switch was shown to be present in both undifferentiated and lineage committed embryonic progenitor cells and was further identified in various other cell types (24-29). This suggests that a conserved, yet unknown, mechanosensitive cellular signaling module regulates myosin II-based cortical contractility and motile cell transformation depending on cellular shape deformations in constrained tissue microenvironments.

\section{Cell contractility levels increase upon cell confinement and regulate migration plasticity}

To approach the question of how cells can measure and adaptively respond to physical cell shape changes within their 3D tissue microenvironments, we established a synthetic approach that enables to mimic mechanical cell deformations in controlled 3D microconfinement assays (30). Primary progenitor stem cells were isolated from blastula stage zebrafish embryos and cultured in planar confinement assays of defined height to mimic various cell deformation amplitudes (Fig. S1A). Lowering confinement height in discrete steps increased cell deformation, which scaled non-linearly with a pronounced enrichment of myosin II at the cell cortex relative to cortical actin accumulation (Fig. 1A,B and Fig. S1B-D; Movie 1). Cortical accumulation of myosin II was accompanied by an increase in cellular bleb size (Fig. S1E, Movie 1), indicative of an active increase in cortical contractility levels depending on confinement height. Myosin II re-localization to the cell cortex in confined cells was rapid $\left(\mathrm{t}_{1 / 2}<1 \mathrm{~min}\right.$, Fig. $\left.1 \mathrm{C}, \mathrm{D}\right)$ and temporally stable under confinement. Of note, distinct plateaus of cortical myosin II enrichment were evident, with myosin II re-localization increasing for larger cell deformations (Fig. 1C). A cell confinement height below $7 \mu \mathrm{m}$ caused a pronounced increase in cell lysis during compression, defining a maximal threshold deformation of $\sim 30 \%$ of the initial cell diameter, given a blastula cell size of d $\sim 25 \mu \mathrm{m}$ (Fig. S3H). Overall, these data support that the physical microenvironment defines a specific set point level of cortical contractility as a function of cell deformation. 
We have previously shown that an increase in myosin II-mediated cortical contractility induced a stochastic motility switch into a highly motile amoeboid migration phenotype termed stable-bleb mode (23). In accordance with these results, rapid cortical myosin II enrichment in confinement resulted in spontaneous cell polarization which initiated amoeboid cell migration (Fig. 1E,F and Fig. S1F,G, Movie 2,3). Polarized cells revealed characteristic actomyosin density gradients from the cell front towards the rear accompanied with fast retrograde cortical flows (Fig. S1H, Movie 2,3). These cortical flows have been shown to power fast amoeboid migration in polarized cells $(23,31)$, while unpolarized cells showed random tumbling with minimal net translocation (Fig. S1F,G, S2A). These data support that physical cell deformation in confinement is sufficient to increase actomyosin network contractility and trigger rapid amoeboid cell migration.

Release of cell compression induced a rapid re-localization of cortical myosin to the cytoplasm (Fig. 1G and S1I), followed by a rapid loss of cell polarization and related migratory capacity (Fig. S1G, Movie 4). Interfering with myosin II activity via Blebbistatin inhibited cell polarization and associated cell motility in confinement (Fig. 1E and S1J), in accordance with a necessary role of myosin II-based contractility in cell polarization and migration induced by mechanical cell shape deformation. Cortical myosin II enrichment and cell polarization occurred independently of caspase activation (Fig. S1K), supporting that morphodynamic changes are not caused by the activation of pro-apoptotic signaling programs. Furthermore, transcriptional inhibition did not block cortical myosin II re-localization and cell polarization (Fig. S1L), indicating that a nongenetic program is regulating cellular morphodynamics under cell compression.

During gastrulation, blastoderm embryonic progenitor stem cells specify into different lineages (ectoderm, mesoderm, endoderm) and acquire distinct biomechanical and morphodynamic characteristics, driving germ layer positioning and shape formation of the embryo $(32,33)$ (Fig. 2A,B). To test the mechanosensitive response to cell deformation at later developmental stages, we obtained different progenitor cell types from embryos via genetic induction or using endogenous reporter lines. Under confinement, non-motile ectodermal cells rapidly polarized and started to migrate in an amoeboid stable-bleb mode. Similarly, mesendodermal cells underwent a fast mesenchymal-to-amoeboid transition in confinement (Fig. 2B-D and Fig. S2A, Movie 3,5). The fraction of polarized stable-bleb cells and their cell speed was comparable for different progenitor cell types in confinement (Fig. S2B,C). Together, these results support that physical cell shape deformation in confined tissue microenvironments activates a mechanosensitive signaling pathway regulating adaptive cortical contractility levels and morphodynamic migration plasticity in pluripotent and lineage committed embryonic stem cells.

\section{The cell nucleus is a mechanosensor of large cell shape deformation}

We next sought to identify potential mechanisms that control cellular shape deformation sensing and adaptive morphodynamic behavior. Cortical myosin II re-localization and amoeboid cell transformation occurred on passivated confinement surfaces independently of adhesive substrate coating (Fig. S2A,C and S3A) and cell-cell contact formation (Fig. S3B). These observations support that the activation of cortical contractility in confinement occurs independently of adhesion-dependent mechano-transduction pathways (34). The temporal characteristics of myosin II re-localization dynamics in confined cells showing a fast, stable and reversible accumulation of cortical myosin II (Fig. 1C,D), suggested that shape deformation is sensed by a 
non-dissipative cellular element that can rapidly measure and convert gradual cellular shape changes into stable contractility response levels.

The actomyosin cytoskeleton itself has been implicated to act as a mechanosensitive network (20), but generally limits deformation sensing due to rapid turnover of the cell cortex (35). To test for the activation of mechanosensitive ion channels we used Gadolinium and GsMTx4, inhibitors of stretch activated channels, with GsMTx4 having been shown to block the tension dependent Piezol channel which is activated following confinement of human cancer cells (36). Treatment with both inhibitors showed no significant reduction in cortical myosin II accumulation under cell deformation (Fig. S3C), despite the presence of functional Piezol channels in these cells as validated with the Piezo1 specific agonist Yoda (Fig. S3D).

Interestingly, we observed that cortical myosin II enrichment only started to occur below a threshold confinement height $(\sim 13 \mu \mathrm{m})$ that correlated with the spatial dimension of the nucleus (Fig. 3A and S3H). Analyzing nuclear shape change versus cortical myosin accumulation revealed a bi-phasic behavior, with a first phase in which the nucleus diameter remained nearly constant and no myosin II accumulation was observed, and a second phase in which the relative myosin accumulation linearly increased with the relative change in nucleus diameter (Fig. 3A,B and S3E). In accordance with this observation, we expected a proportional change of nuclear surface ruffling upon deformation of an initially spherical nucleus. Measuring of nuclear surface folding by the expression of the inner nuclear membrane (INM) protein Lap2b-eGFP revealed that membrane ruffling was continuously reduced when nucleus deformation started to occur at a threshold deformation of $\sim 13 \mu \mathrm{m}$ (Fig. 3C-E and S3F, Movie 6). In addition, analysis of nucleus membrane curvature for confined versus control cells in suspension indicated INM surface unfolding (Fig. 3F, G, Movie 6), with no significant difference in total nuclear volume and surface (Fig. S3G). Nucleus deformation further correlated with cortical myosin II accumulation in the endogenous in vivo context during the blastula to gastrula transition, when a gradient of cellular packing density appears from the animal pole towards the lateral margin (37) (Fig. S2D,E).

To further probe the dependence of cortical myosin II accumulation on nucleus size, we dissociated primary embryonic stem cells from early and late blastula stages as cells reduce their size in consecutive rounds of early cleavage divisions (Fig. S3H). Deforming cells of different sizes under similar confinement heights revealed that myosin II accumulation is correlated with relative changes in nucleus deformation but not cell deformation (Fig. 4A,B). To test a functional role of the nucleus in regulating cortical contractility levels during cellular shape deformation, we analyzed cortical myosin II accumulation in mitotic cells that present a disassembled nuclear envelope. To arrest cells in mitosis and further increase the percentage of mitotic cells, we used Nocodazole, a microtubule disrupting drug. Confinement of mitotic cells (either spontaneous or Nocodazole-induced) did not trigger a cortical myosin II accumulation at $7 \mu \mathrm{m}$ confinement height compared to interphase blastula cells (Fig. 4C) or cell polarization (Fig. S3I), although they accumulated myosin II (Fig. 4D) and polarized (Fig. S3I) in response to LPA, a potent activator of Rho/Rock signaling that has previously been shown to induce rapid cortical myosin II enrichment and amoeboid migration in zebrafish embryonic progenitor stem cells (23). During entry into mitosis, cells further gradually lost cortical myosin II accumulations which temporally correlated with the start of nuclear envelop breakdown (Fig. 4E). Altogether, these data show that myosin II enrichment is associated with nuclear shape deformation and stable INM membrane unfolding. This suggests that the nucleus functions as a continuous non-dissipative sensor element 
of cell deformation involved in the mechanosensitive regulation of cortical contractility levels and cellular morphodynamics.

To directly test biophysical characteristics of the nucleus, we developed an assay to probe intracellular nucleus mechanics by optical tweezer measurements. For this purpose, latex beads of $1 \mu \mathrm{m}$ size were injected into 1-cell stage embryos that dispersed across embryonic cells during early cleavage cycles and acted as intracellular force probes to measure rheological properties of the nucleus (Fig. S4A). Trapezoidal loads were measured for cells in suspension and under $10 \mu \mathrm{m}$ confinement (Fig. S4B-E). The recorded force followed the fast-initial indentation to reach a peak force before it relaxed to a non-zero constant force-plateau. The relaxation time remained unchanged between suspension $(\tau=6.08 \mathrm{~s}+/-1.1 \mathrm{~s})$ and confined cells $(\tau=4.00 \mathrm{~s}+/-0.6 \mathrm{~s})$ (Fig. S4D$\mathrm{H}$ ), suggesting a passive but rapid (second scale) relaxation of a viscous component. The forceplateau on long timescale corresponds to an elastic component of the nucleus (Fig. S4I), in line with previous measurements that identified an elastic behavior of the nucleus (38) that can act as a cellular strain-gauge. In addition, we observed that INM unfolding was stable over a measurement period of $60 \mathrm{~min}$ (Fig. S4J) under mechanical cell deformation, supporting that INM stretch does not relax over extended time periods.

\section{Nuclear deformation activates a calcium-dependent mechanotransduction pathway regulating myosin II activity}

We next aimed at identifying nucleus deformation-dependent signaling pathways that link the spatio-temporal correlation of nuclear shape changes with fast myosin II activation and changes in morphodynamic cell behavior. Our previous observations suggested that nucleus deformation and associated mechanosensitive processes at the INM interface are involved in the regulation of myosin II activity and cortical contractility. Among a set of molecules tested under confinement conditions (Table S1), we identified cytosolic phospholipase A2 (cPLA 2$)$ as a key molecular target mediating the activation of cortical myosin II enrichment (Fig. 5A-B) and amoeboid cell transformation under cell compression (Fig. 5C). Inhibition of $\mathrm{cPLA}_{2}$ by pharmacological interference using Pyrrophenone robustly blocked cortical myosin II re-localization under varying confinement heights (Fig. S5A). Furthermore, we observed a significant reduction of cortical myosin II levels in confined cells by morpholino (MO) interference with cPLA 2 , while overexpression of $\mathrm{cPLA}_{2}$ mRNA rescued the morphant phenotype and led to a comparable myosin II accumulation as in control cells (Fig. 5A,B). Residual myosin II activation in cells obtained from morphant embryos suggests a maternal contribution of cPLA2 protein in the early embryo which cannot be targeted by MO interference. To exclude that other mechanisms such as structural changes in the actin network prevent cortical myosin II re-localization under cPLA 2 inhibition, we added LPA as an exogenous myosin II activator to cPLA 2 inhibited cells. Under this condition, myosin II was strongly accumulated at the cell cortex (Fig. S5B,C) and induced cell polarization associated with amoeboid motility (Fig. 5C). These data support that myosin II can be activated by extrinsic pathways when cPLA 2 signaling is inhibited and remains competent to bind to the cell cortex.

Recent work identified that the activation of pro-inflammatory signaling during leucocyte recruitment to wounding sites is regulated by tension-sensitive binding of cPLA 2 to the INM (39). We thus tested a role of $\mathrm{cPLA}_{2}$ in the nucleus by generating a modified cPLA 2 construct containing a nuclear export sequence (NES). Using Leptomycin B as a blocker of nuclear export, an 
accumulation of cPLA $_{2}$-NES-GFP within the nucleus was observed, showing a concomitant increase of cortical myosin II levels in confined cells (Fig. 6A,B). These data support, that cPLA2 localization in the nucleus is required for myosin II enrichment at the cortex.

We further validated that cortical myosin II enrichment in cells of different sizes (early versus late blastula cells) and different embryonic cell lineages (mesendoderm/ectoderm cells) depends on the activation of $\mathrm{cPLA}_{2}$ signaling. Pharmacological inhibition of $\mathrm{cPLA}_{2}$ activity blocked cortical myosin re-localization in confined cells (Fig. 6C) and strongly reduced cell polarization and associated migration competence (Fig. S2B), supporting a consistent role of cPLA 2 activation under physical cell deformation across early to late developmental stages. These data support that activation of $\mathrm{cPLA}_{2}$ signaling in the nucleus mediates adaptive cytoskeletal and morphodynamic behavior under cell deformation.

Arachidonic acid (AA) is the primary cleavage product generated by cPLA 2 activity (40). To directly validate whether nucleus deformation in confinement triggers $\mathrm{cPLA}_{2}$ activity, we measured the release of AA by Raman spectroscopy. The analysis of Raman spectra confirmed the specific production of AA in confined cells (Fig. 6D and Fig. S5E), with the increase in AA production in confined versus control cells being specifically blocked in the presence of cPLA 2 inhibitor (Fig. 6E). We further observed that AA was exclusively detected in the cytoplasm of confined cells, arguing that AA is directly released from nuclear membranes into the cytoplasm. These data support that cell confinement leads to enhanced cPLA 2 activity and production of arachidonic acid associated with INM unfolding and stretching of the nucleus surface.

AA has been implicated to regulate myosin II activity both directly (41) and indirectly via protein phosphorylation (42). We tested the involvement of Rho/Rho associated protein kinase (ROCK) and Calcium/Myosin light chain kinase (MLCK) signaling that act as key regulatory pathways of myosin II activity (4). MLCK inhibition showed no significant effect on myosin II enrichment in confined cells, while a pronounced reduction of cortical myosin II recruitment was observed when using Staurosporin, a general kinase inhibitor, and under specific inhibition of Rho activity (Fig. 6F). Using a RhoA-Fret sensor further indicated an increased RhoA activity in confined cells versus control cells in suspension which was significantly reduced in the presence of cPLA 2 inhibitor in confined cells (Fig. S5F). These data support that AA production by cPLA 2 activity engages upon nuclear envelope unfolding, regulating phosphorylation-dependent myosin II activity at the cell cortex. AA and its metabolic products have been widely implicated in para- and autocrine signaling functions involving GPCRs (43). We assessed the role of AA product release by compressing cells directly under micropillars at an approximate height of $7 \mu \mathrm{m}$, leading to confined and non-confined cells in close proximity (Fig. S5G). Interestingly, while confined cells showed high levels of cortical myosin II and amoeboid cell transformation, non-confined cells in direct contact revealed no alterations in cortical myosin II and cellular morphodynamics (Fig. $\mathrm{S} 5 \mathrm{H}$ ). These results support that $\mathrm{cPLA}_{2}$-dependent myosin II activation does not depend on the release of diffusible signals and regulates cellular morphodynamics via a cell autonomous increase of cortical contractility under cell deformation in confinement.

40 Interference with intracellular calcium levels by addition of BAPTA-AM or in combination with cPLA $_{2}$ inhibitor blocked myosin II enrichment in confined cells, without altering cortical myosin II levels in unconfined control cells (Fig. S5I). LPA stimulation of BAPTA-AM treated cells confirmed that myosin II can be activated by the Rho-ROCK signaling pathway in the absence of intracellular calcium and remains competent to bind the cell cortex (Fig. S5C). Similarly, chelating extracellular calcium reduced cortical myosin II re-localization, while depletion of internal 
calcium stores using Thapsigargin led to a slight increase in myosin II enrichment in confinement (Fig. S5I). The addition of ionomycin showed that high intracellular calcium levels, in the absence of cellular shape deformation, were not sufficient to evoke AA production (Fig. S5J) and cortical myosin II enrichment (Fig. S5B,D). This suggests that intracellular calcium has a permissive function for $\mathrm{cPLA}_{2}$ association with the INM and increasing cortical contractility under cell confinement. Our findings are in line with the observation that $\mathrm{CPLA}_{2}$ contains a calciumdependent C2 domain that modulates protein binding to the INM (44-46), which has been shown to get further enhanced and stabilized by mechanical stretching of the nucleus (39). Consistently, cPLA $_{2}$ showed a transient localization to the INM in the presence of ionomycin, while additional mechanical stretch due to hypotonic swelling or cell confinement induced a stable association with the INM (Fig. S3J-K).

\section{INM unfolding and nucleus positioning enable to decode different types of cell shape deformations}

To study if INM unfolding under cell confinement was sufficient to trigger cPLA 2 activity, we measured cortical myosin II levels and amoeboid migration competence under hypotonic swelling of cells. Quantification of nuclear shape parameters (size, volume, surface) revealed that hypotonic swelling induced comparable nuclear surface expansion and INM unfolding as nucleus deformation under a confinement height of $7 \mu \mathrm{m}$ (Fig. S6A-C). Interestingly, cortical myosin II levels in hypotonic conditions (Fig. 7A, Movie 7) and associated changes in bleb size (Fig. S6D) and cell polarization rate (Fig. 7C) were significantly lower compared to cells deformed at $7 \mu \mathrm{m}$ confinement height. These observations suggest that nuclear envelope unfolding alone is not sufficient to trigger high levels of cortical myosin II enrichment under isotropic cell stretching in hypotonic conditions versus anisotropic cell deformation in confinement.

Comparing intracellular calcium levels between deformed cells in confinement and under hypotonic conditions showed a pronounced increase in intracellular calcium concentrations in confined cells, with a specific calcium increase in the cell nucleus (Fig. 7B and Fig. S6E). Of note, ectopically increasing intracellular calcium levels under hypotonic conditions via the addition of ionomycin led to a pronounced and rapid increase in cortical myosin II enrichment in a cPLA2dependent manner (Fig. S6F, Movie 7) that triggered spontaneous cell polarization (Fig. 7C,D and S6G). Similar to cells in confinement, cell polarization under this condition was associated with a rapid transformation of non-motile cells into a highly motile stable-bleb amoeboid mode with fast migration speed under confinement ex vivo and in vivo (Fig. 7E and S6H,I,M, Movie 7,8). Raman spectroscopy to directly measure cPLA 2 activity confirmed that hypotonic stress increased AA levels (Fig. S5K) in a cPLA 2 -dependent manner (S5L), with addition of ionomycin in hypotonic conditions further increasing AA production (S5M). Relative measured AA levels further directly correlated with cortical myosin II levels (Fig. S5N). Together, these data reveal that different mechanical shape deformations regulate intracellular calcium levels and modulate cPLA $\mathrm{A}_{2}$ activity under similar INM stretch: uniaxial compression in confinement induces high intracellular calcium levels specifically in the nucleus, while isotropic radial stretch in hypotonic stress conditions leads to a lower intracellular calcium levels. Independently modulating nucleus deformation and calcium levels under different shape deformations confirmed that both parameters engage synergistically to regulate cortical contractility (Fig. 8A) and cellular dynamics under mechanical stress (Fig. 7E), thereby enabling a cell to distinguish between different types of shape deformation and to acquire a specific morphodynamic response. 
Intracellular nucleus positioning appeared a promising candidate to differentially modulate calcium levels. ER-plasma membrane (ER-PM) proximity has been implicated as an important regulator of cellular calcium signaling (47). Visualization of membrane proximal ER structures showed that the ER was highly dynamic under conditions of low confinement but was increasingly immobilized between the nucleus-PM interface for larger cell deformations in confinement (Movie 9). In addition, the expanding nucleus contact area close to the plasma membrane closely correlated with an intracellular calcium increase (Fig. S6J). We speculated that STIM-Orai, with STIM proteins located at the endoplasmic reticulum (ER) and Orai proteins representing calciumselective plasma membrane (PM) calcium channels, could be involved in cellular calcium regulation in confined cells. STIM-Orai proteins have an established function in store operated calcium entry (SOCE) upon depletion of calcium from the ER which are mediated via ER-PM proximity $(48,49)$. Analysis of STIM-Orai protein localization revealed that both proteins accumulate at the interface between the nucleus and plasma membrane in confined cells at $7 \mu \mathrm{m}$ (Fig. S6K,L). In contrast, we observed a homogenous distribution of both channels in cells under $13 \mu \mathrm{m}$ confinement height when the ER was not spatially confined between the nucleus and PM. These data support that ER immobilization is associated with the specific enrichment of STIMOrai in the ER-PM contact region where mechanical ER confinement occurs. Inhibition of the STIM-Orai complex by using 2APB further blocked myosin II enrichment under cell deformation in confinement (Fig. S5I). Our observations support that mechanical compression of the cell nucleus induces a tight connectivity between ER-PM structures and STIM-Orai localization at the ER-PM contact interface involved in the upregulation of intracellular calcium levels in confined cells.

\section{Conclusions}

Our data support that the nucleus establishes a core element to measure cellular shape deformation via two key physical parameters: 1) nuclear shape deformation leading to INM unfolding and 2) intracellular spatial positioning of the nucleus. In this model, INM unfolding under nuclear shape change allows for the deformation-dependent activation of $\mathrm{cPLA}_{2}$ signaling, whereby $\mathrm{cPLA}_{2}$ activity is modulated by intracellular calcium levels set by nucleus-PM proximity (Fig. $8 \mathrm{~B}$ and S7A). The parameter space of these two variables (INM unfolding and calcium levels) provides a unique identifier for a cell to decode distinct shape deformations as exemplified on anisotropic cell deformation in confinement versus isotropic hypotonic cell stretching, allowing cells to acquire a unique adaptive response depending on the type of physical shape deformation (Fig. S7B).

Biochemical, physical and mechanical cues in the surrounding of a cell create manifold information for cells which is continuously sensed, integrated and transduced to allow for complex cellular functioning. Here we show that the cell nucleus functions as a cellular mechano-gauge for precisely decoding cellular shape changes, allowing cells to adaptively and rapidly tune cytoskeletal network properties and morphodynamic behavior within their $3 \mathrm{D}$ tissue microenvironment during development. This mechanism lays a foundation for functional principles underlying cellular proprioception that, comparable to the sensing of spatio-temporal changes in body posture and movement (50), enable a precise interpretation of shape changes on the single cell level.

The nucleus, being the largest organelle within the cell, represents a prominent structure to transmit and modulate mechanosensitive processes (51-55), and nucleus deformation has been shown to 
influence nuclear transport and cell differentiation (56-58), chromatin organization (59-61), migration (62-66) and pathfinding in constrained environments (67). Our findings support that nucleus deformation and its intracellular positioning establish a cellular sensing module that equips cells to rapidly and reversibly adapt their dynamic response to shape fluctuations. This "nuclear ruler pathway" was also identified in an accompanying study (68), supporting its conservation between embryonic and differentiated cells in the adult organism. The observation of a rapid contractile cell response upon cell squeezing in confinement which is followed by fast amoeboid motility is reminiscent of a "cellular escape reflex" that enables cells to cope with physical constraints and acute deformations of their shape. Such a mechanism might be relevant for various biological processes associated with migration plasticity of cancer and immune cells in constrained 3D tissue niches (69-72) mechano-chemical feedback processes during morphogenesis (73) and homeostatic tissue functions such as cell density regulation (74), which require accurate mechanisms to detect variations in cellular size and shape and multicellular packing density in crowded 3D tissues.

Acknowledgments: The authors would like to acknowledge the Super Resolution Light Microcopy and Nanoscopy (SLN) Facility of ICFO for their support with imaging experiments and Johann Osmond (Nanofabrication laboratory, ICFO) for the design and production of molds for generating confinement coverslip, and further support from the CRG Core Facilities for Genomics and Advanced Light Microscopy. We thank the following labs that kindly provided plasmids: pCS2+ lefty/casanova (courtesy Carl-Philipp Heisenberg); pCS2+ lyn-TdTomato (courtesy Berta Alsina); pTriEx-RhoA FLARE.sc Biosensor WT was a gift from Klaus Hahn (Addgene plasmid \#12150; RRID:Addgene_12150). We would like to thank Carl-Philipp Heisenberg, Matthieu Piel and Alexis J. Lomakin for discussions on this work and Ben Lehner, Vivek Malhotra, Sebastian P. Maurer and the Ruprecht and Wieser lab members for critical reading of the manuscript. Funding: V.V. acknowledges support from the ICFOstepstone - PhD Programme funded by the European Union's Horizon 2020 research and innovation programme under the Marie Skłodowska-Curie grant agreement No 665884. F.P. and Q.T. acknowledge a grant funded by "The Ministerio de Ciencia, Innovación y Universidades and Fondo Social Europeo (FSE)" (BES2017-080523-SO, PRE2018-084393). M.A.V. acknowledges support from the Spanish Ministry of Science, Education and Universities through grants RTI2018-099718-B100 and an institutional "Maria de Maeztu" Programme for Units of Excellence in R\&D and FEDER funds. J.W. was suppported by the Christian Doppler Forschungsgesellschaft (Josef Ressel Center for Phytogenic Drug Research). S.W. and M.K. acknowledge support from the Spanish Ministry of Economy and Competitiveness through the "Severo Ochoa" program for Centres of Excellence in R\&D (SEV-2015-0522), from Fundació Privada Cellex, Fundación MigPuig and from Generalitat de Catalunya through the CERCA program and LaserLab (No 654148). M.K. acknowledges support through Spanish Ministry of Economy and Competitiveness (RYC2015-17935, EQC2018-005048-P, AEI-010500-2018-228, PGC2018-097882-A-I00), Generalitat de Catalunya (2017 SGR 1012), the ERC (715243) and the HFSPO (CDA00023/2018). S.W. acknowledges support through the Spanish Ministry of Economy and Competitiveness via MINECO's Plan Nacional (BFU2017-86296-P). V.R. acknowledges support from the Spanish Ministry of Economy and Competitiveness through the Program "Centro de Excelencia Severo Ochoa 2013-2017', the CERCA Programme / Generalitat de Catalunya, MINECO's Plan Nacional 45 (BFU2017-86296-P). Author contributions: V.R. and S.W. designed research; V.V. performed key experiments and data analysis; F.P. contributed to hypotonic and interference experiments and 


\section{Science}

RNA preparations; F.C-C. and V.V. performed optical tweezers experiments and F.C. analyzed the data; M.M. and V.V. performed Raman experiments and M.M. analyzed the data; M.C-R. analyzed the Lap2B-GFP data; H-M.M. and Q.T.-R. performed in vivo experiments and H.-M.H. performed injections and helped with mesendoderm-ectoderm experiments; S.J-D. cloned plasmids, synthetized mRNA and performed mRNA and bead injections; S.P-L. performed calcium imaging related to the role of Piezo channels; M.A.V. supervised S.P-L. and contributed with discussions and support to calcium imaging experiments; J.W. provided biological reagents and supported molecular cloning. M.K. supervised F.C.-C. and designed tweezer experiments. S.W. and V.R. supervised the project, contributed to data analysis and wrote the manuscript. Competing interests: The authors declare no competing financial interests. Data and materials availability: All data relevant for the conclusions of this work are available in the main text or the supplementary materials.

\section{Supplementary Materials:}

15

Supplementary Methods

Figures S1-S7

Supplementary Table S1

Supplementary Movies S1-S9

Supplementary References (80-86) 


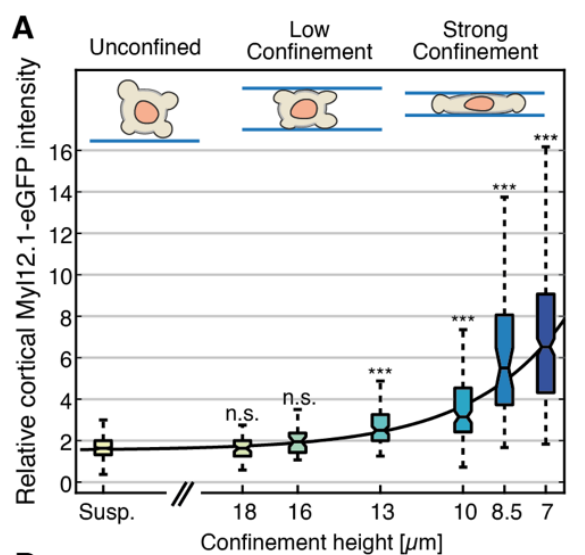

B
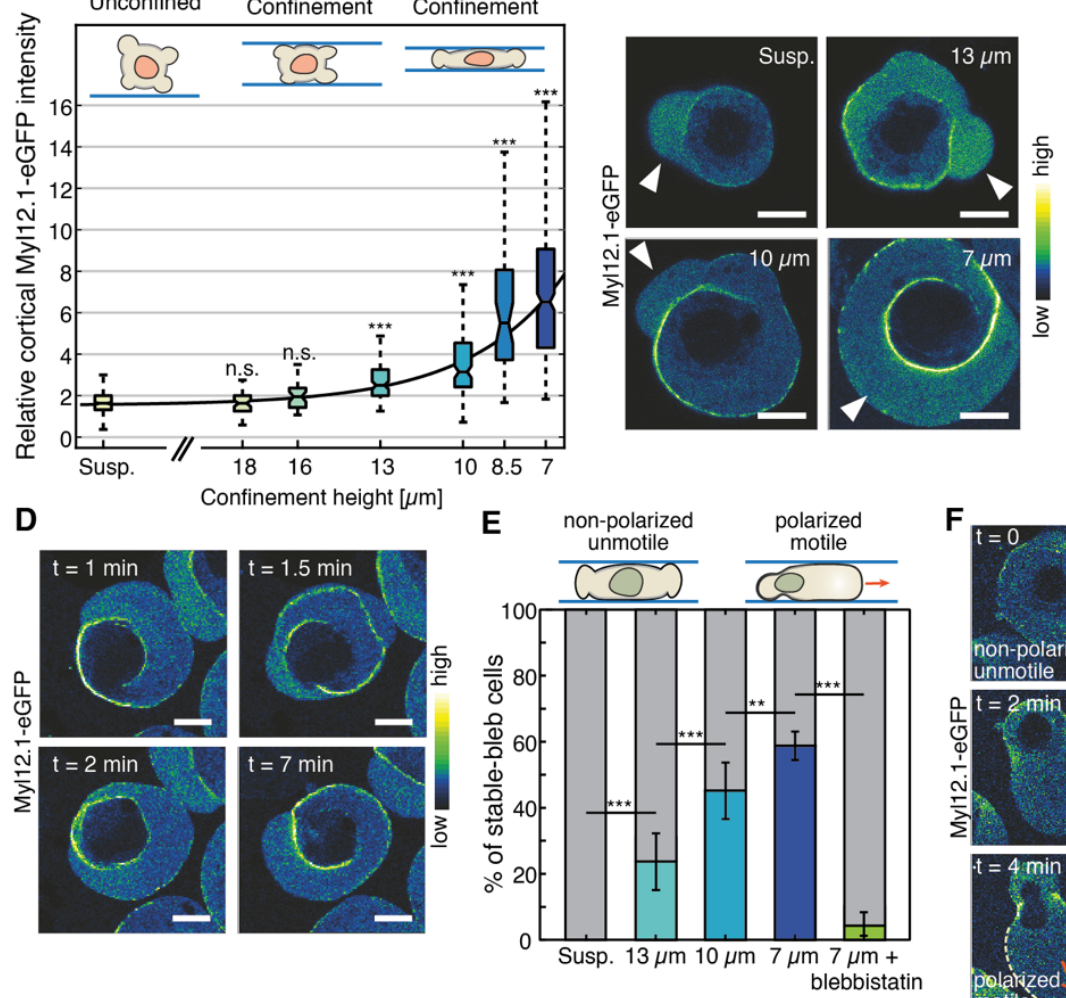
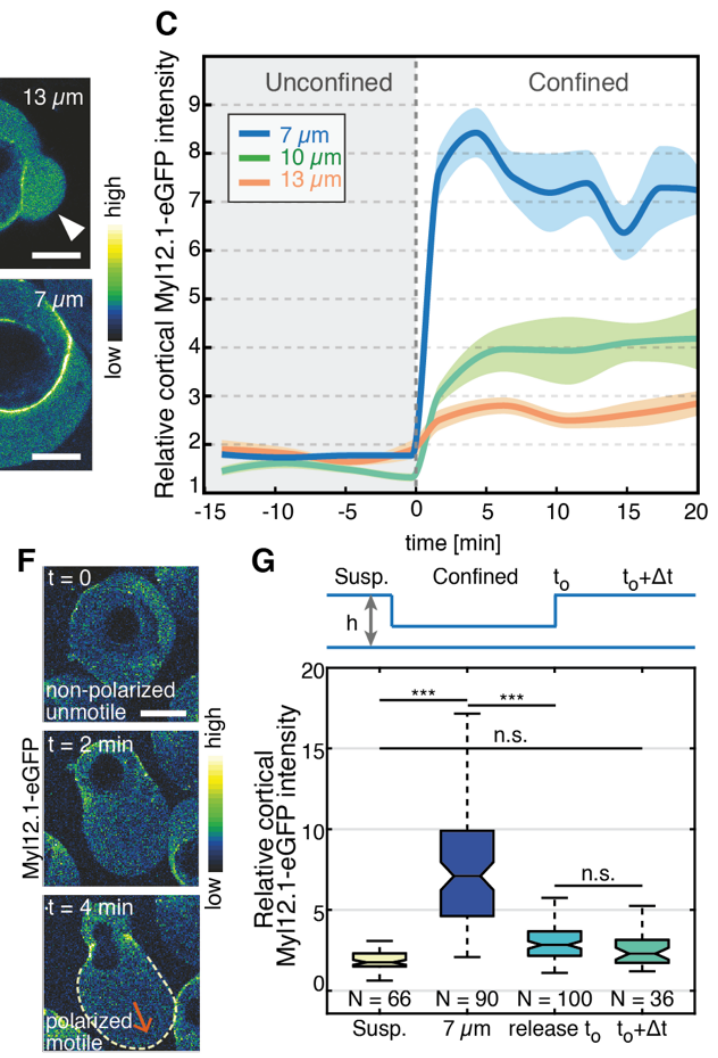

Figure 1. Cell deformation in confined environments defines cell contractility, polarization

and fast amoeboid cell migration. (A) Relative cortical myosin II enrichment for decreasing confinement height in un-polarized progenitor cells $(\mathrm{N}=477$ (suspension, unconfined); $\mathrm{N}=56$ (18 $\mu \mathrm{m}) ; \mathrm{N}=35(16 \mu \mathrm{m}) ; \mathrm{N}=103(13 \mu \mathrm{m}) ; \mathrm{N}=131(10 \mu \mathrm{m}) ; \mathrm{N}=49(8.5 \mu \mathrm{m}) ; \mathrm{N}=348(7 \mu \mathrm{m}))$. Significance values are with respect to the suspension condition. Black line shows a monoexponential fit with offset to the data. (B) Exemplary confocal fluorescence images of control progenitor stem cells in suspension (Susp.) and indicated confinement heights expressing Myl12.1eGFP (myosin II). White arrows point at cellular blebs. (C) Temporal dynamics of cortical myosin II recruitment upon mechanical confinement at time $\mathrm{t}=0$ at indicated heights. Thick lines correspond to the mean and areas to the standard error of the mean (sem). $\mathrm{N}>50$ cells for all conditions. (D) Exemplary cross-sectional time-lapse images of myosin II-eGFP expressing cells under $7 \mu \mathrm{m}$ confinement. (E) Percentage of polarized motile stable-bleb cells in suspension at 


\section{Science}

indicated confinement heights and myosin II inhibition (blebbistatin) at $7 \mu \mathrm{m}$ (each $\mathrm{N}>500$ ). (F) Representative time-lapse images of a myosin II-eGFP expressing cell undergoing spontaneous stable-bleb cell polarization and migration initiation. Dashed line shows the stable-bleb cell front and red arrow points in the direction of movement. (G) Relative cortical myosin II enrichment during reversible cell confinement. Cells were confined for $15 \mathrm{~min}$ before confinement was released and cortical myosin II levels were measured at $\mathrm{t}_{0}(0-5 \mathrm{~min})$ and at $\mathrm{t}_{0}+\Delta \mathrm{t}(30-60 \mathrm{~min})$ after release. ${ }^{* * *} \mathrm{p}<0.0001,{ }^{*} \mathrm{p}<0.001,{ }^{*} \mathrm{p}<0.01$, not significant (n.s.). All scale bars $10 \mu \mathrm{m}$. 


\section{Science}

MAAAS

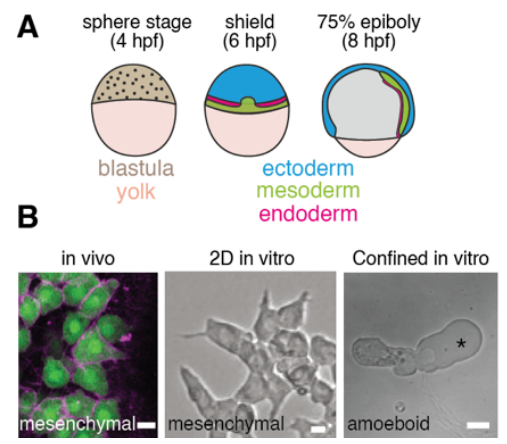

C
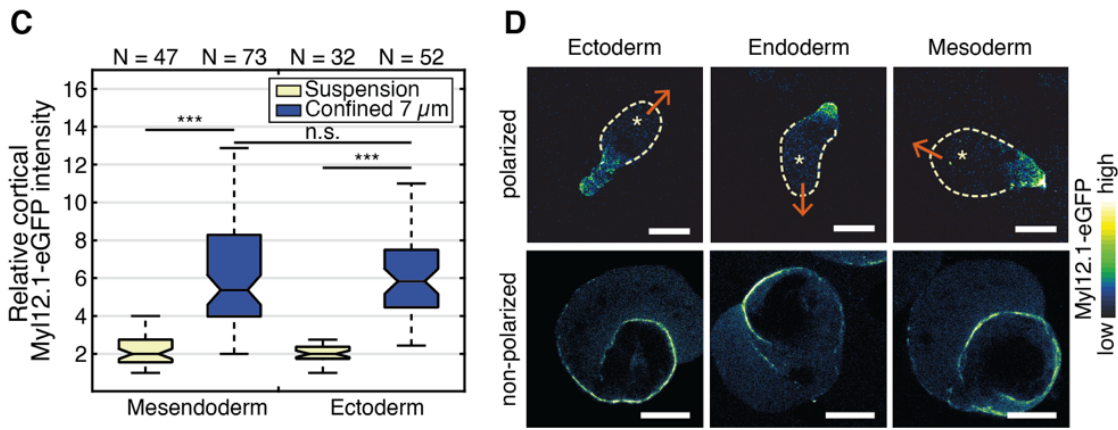

Figure 2. Physical confinement triggers amoeboid migration in different cell lineages. (A)

Sketch of the developing zebrafish embryo at sphere (4 hpf), shield (6 hpf) and 75\% epiboly (8 hpf) stage. (B) Exemplary confocal and bright field images of mesodermal cells in vivo expressing Lyn-Tomato (magenta, membrane) and GFP (green) under the mezzo promoter (left), induced mesendodermal cells in vitro plated on a 2D fibronectin-coated surface (middle) and under $7 \mu \mathrm{m}$ confinement (right), asterisk points at stable-bleb cell front. (C) Relative cortical myosin II intensity for mesendodermal and ectodermal progenitor cells in control suspension and confinement conditions. (D) Exemplary confocal images of stable-bleb polarized (top) and nonpolarized (bottom) progenitor cell types expressing myosin II-eGFP under $7 \mu \mathrm{m}$ confinement. From left to right: ectoderm, endoderm and mesoderm cells. Dashed line and yellow asterisks indicate the stable-bleb cell front and red arrows the direction of cell migration. $* * * p<0.0001$, $* * \mathrm{p}<0.001, * \mathrm{p}<0.01$, not significant (n.s.). All scale bars $10 \mu \mathrm{m}$. 
A

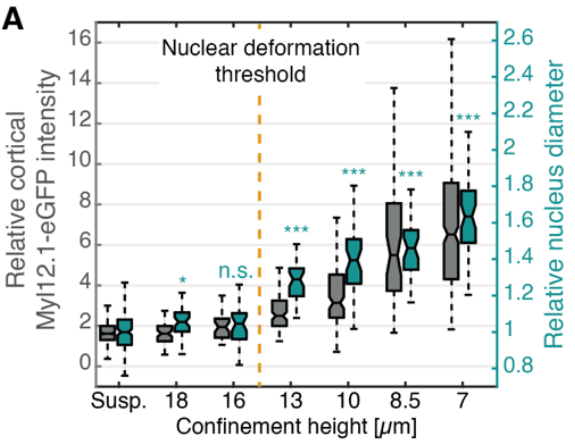

$D_{E} \quad N=54 N=33^{3}=30{ }^{0} N=29 \quad E$

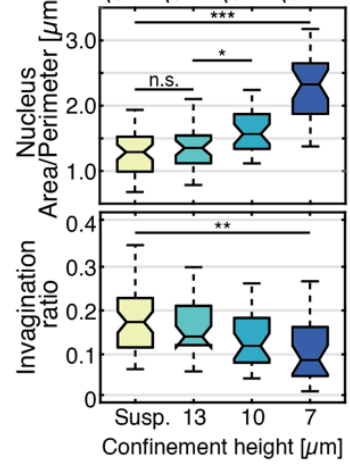

B

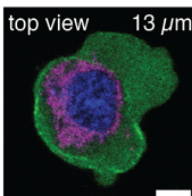

top view
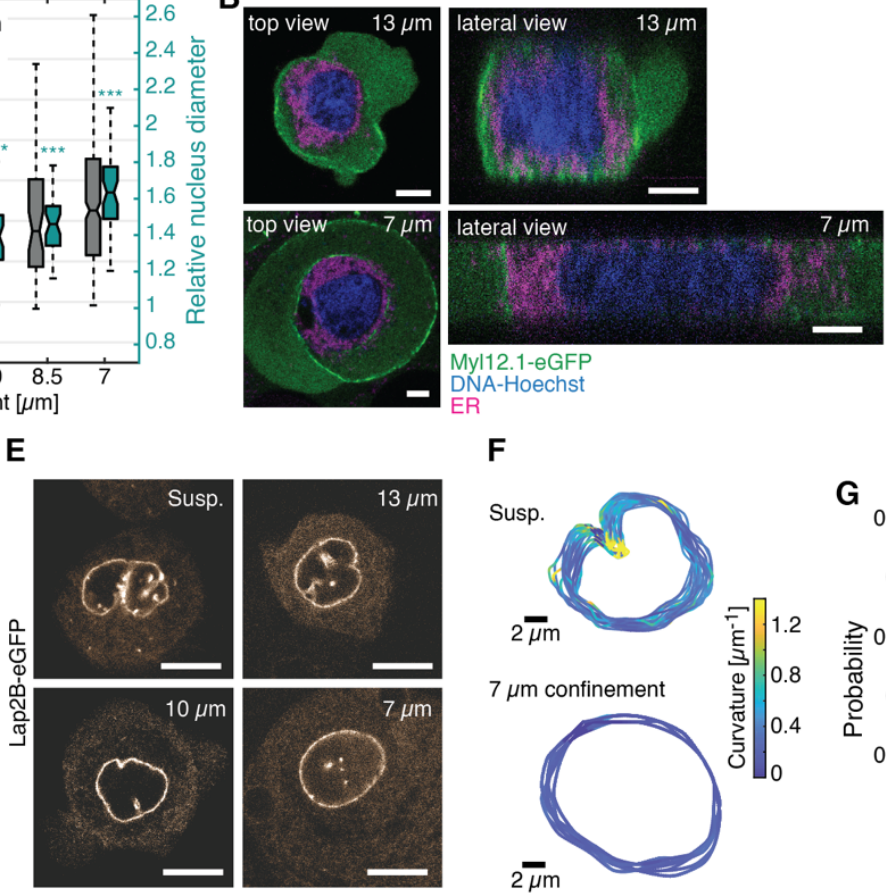

$\mathbf{F}$

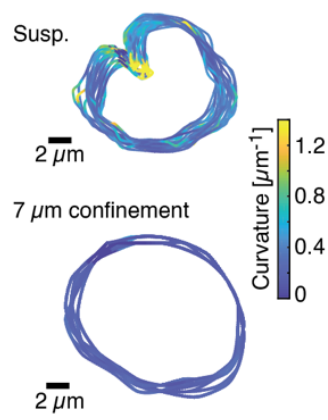

C
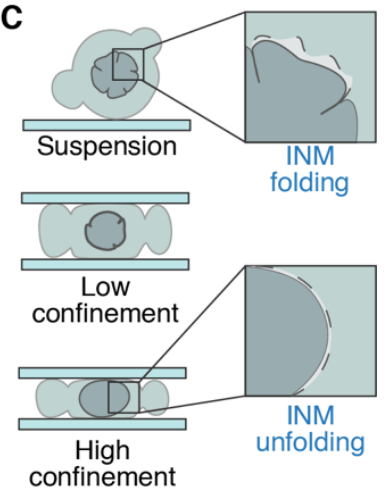

G

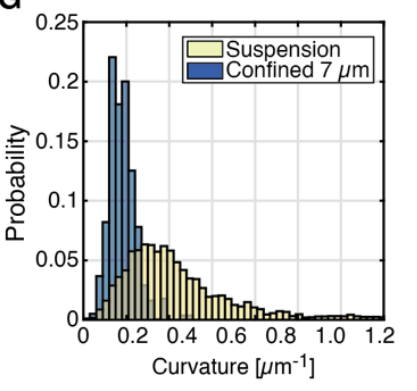

Figure 3. Nuclear envelop unfolding is associated with increasing cortical contractility. (A)

Double boxplot of relative cortical myosin II enrichment (left axis, grey) and relative nuclear diameter (right axis, green) for decreasing confinement height. Statistical test for relative nuclear diameter performed with respect to suspension $(\mathrm{N}=144$ (suspension); $\mathrm{N}=44(18 \mu \mathrm{m}) ; \mathrm{N}=32(16$ $\mu \mathrm{m}) ; \mathrm{N}=37(13 \mu \mathrm{m}) ; \mathrm{N}=45(10 \mu \mathrm{m}) ; \mathrm{N}=37(8.5 \mu \mathrm{m}) ; \mathrm{N}=50(7 \mu \mathrm{m}))$. Statistical tests for cortical myosin II levels and experimental $\mathrm{N}$ related to Fig.1A. (B) Exemplary confocal top views (x-y) and lateral views (y-z) of progenitor stem cells expressing myosin II-eGFP stained with DNAHoechst and ER-TrackerRed in $13 \mu \mathrm{m}$ and $7 \mu \mathrm{m}$ confinement. (C) Illustration showing the unfolding of the inner nuclear membrane (INM) with increasing cell confinement. (D) Nuclear area to perimeter ratio (top) and nuclear invagination ratio (bottom) for increasing confinement. (E) Exemplary confocal images of cells expressing Lap2B-eGFP under varying cell deformation. (F) Curvature analysis of nuclear shape for 20 consecutive frames $\left(\mathrm{t}_{\mathrm{lag}}=10 \mathrm{~s}\right)$ for unconfined (suspension, top) and $7 \mu \mathrm{m}$ confined nuclei (bottom). (G) Histogram of nuclear curvature for 


\section{Science}

unconfined and $7 \mu \mathrm{m}$ confined nuclei related to panel $\mathrm{F}$ with $\mathrm{N}=10$ cells for each condition $\left(\mathrm{p}<10^{-}\right.$ $12, * * *) . * * * \mathrm{p}<0.0001, * * \mathrm{p}<0.001, * \mathrm{p}<0.01$, not significant (n.s.). All scale bars $10 \mu \mathrm{m}$ despite $5 \mu \mathrm{m}$ in $(\mathrm{B})$. 
A
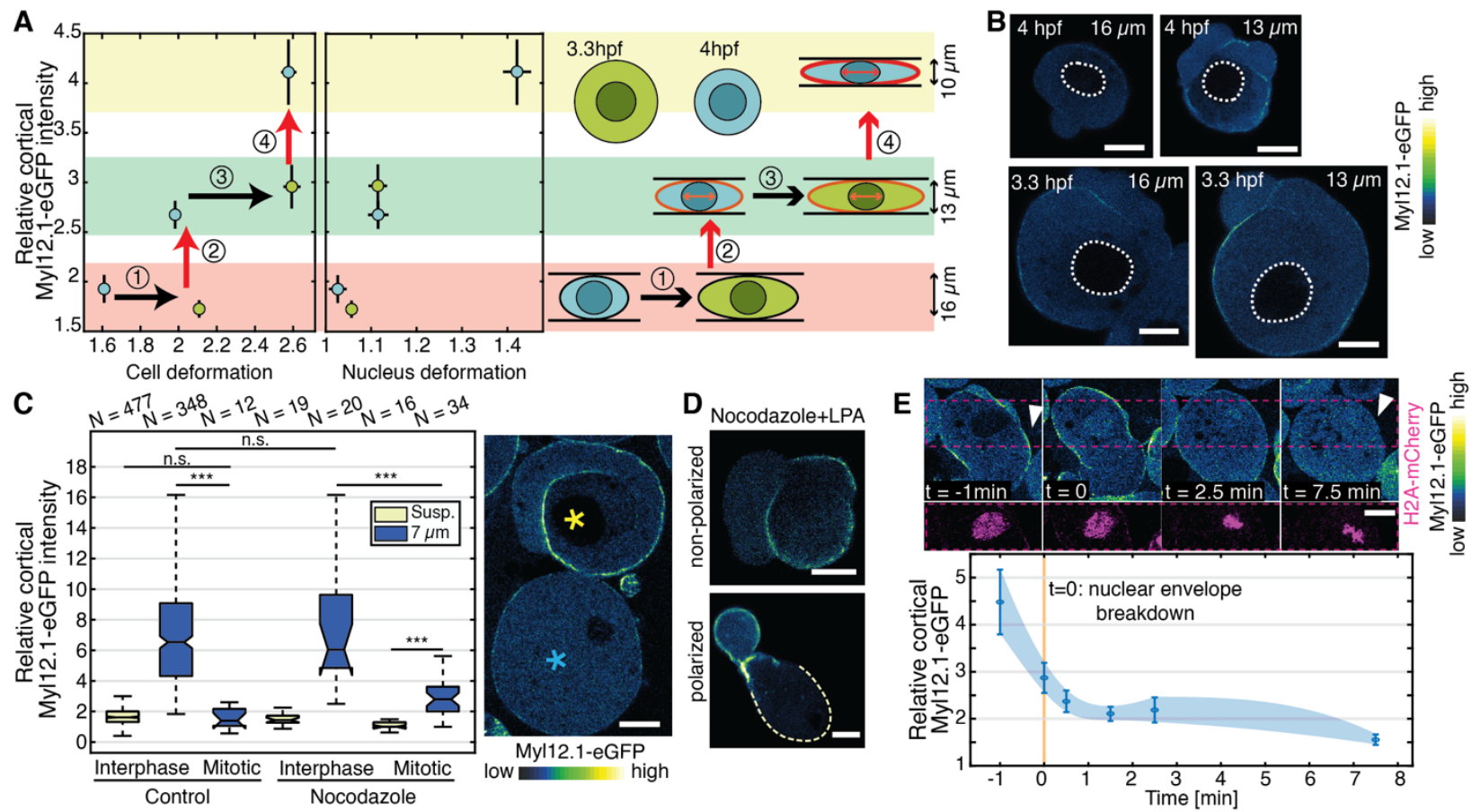

Figure 4. Nucleus size and integrity determine the morphodynamic cell response to confinement. (A) Relative cortical myosin II intensity with respect to cell deformation as defined by the ratio of cell size/confinement height (left) and nucleus deformation (right) measured via relative nucleus diameter increase (right) for cells dissociated from embryos at high-oblong (3.3 hpf) and sphere stage (4 hpf) and cultured under similar confinement heights as indicated. Data points and error bars indicate mean and standard error of the mean (sem); (3.3 hpf: $16 \mu \mathrm{m}$ $\mathrm{N}=58,13 \mu \mathrm{m} \mathrm{N}=61 ; 4$ hpf: $16 \mu \mathrm{m} \mathrm{N}=44,13 \mu \mathrm{m} \mathrm{N}=60,10 \mu \mathrm{m} \mathrm{N}=45)$. The Pearson correlation coefficient in between myosin II intensity and nuclear deformation is 0.48. (B) Exemplary confocal images of progenitor cells expressing myosin II-eGFP under $16 / 13 \mu \mathrm{m}$ confinement dissociated from 4 hpf (top) and 3.3 hpf (bottom) embryos. Dashed lines outline cell nuclei. (C) Relative cortical myosin II enrichment for interphase and mitotic cells under $7 \mu \mathrm{m}$ confinement cultured in suspension (control) in the presence of $1 \mu \mathrm{M}$ Nocodazole. Exemplary confocal images of progenitor cells expressing myosin-II-eGFP in interphase (yellow asterisk) or during mitosis (cyan 


\section{Science}

asterisk) under $7 \mu \mathrm{m}$ confinement. (D) Exemplary confocal images of progenitor unpolarized (top) and polarized (bottom) cells expressing myosin-II-eGFP during mitosis treated with $1 \mu \mathrm{M}$ Nocodazole and $50 \mu \mathrm{M}$ LPA. Dashed line shows the stable-bleb cell front. (E) Cortical myosin II intensity of $\mathrm{N}=7$ cells undergoing mitosis and representative confocal time lapse images of cells expressing myosin-II-eGFP and H2A-mCherry at indicated time points $(\mathrm{t}=0$ : time of nuclear envelope breakdown). The arrows point at the cell cortex with cortical myosin enrichment $(\mathrm{t}=-$ $1 \mathrm{~min})$ or loss of cortical myosin levels $(\mathrm{t}=7.5 \mathrm{~min})$. Data points and error bars indicate mean and standard error of the mean. $* * * \mathrm{p}<0.0001, * * \mathrm{p}<0.001, * \mathrm{p}<0.01$, not significant (n.s.). All scale bars $10 \mu \mathrm{m}$. 


\section{Science}
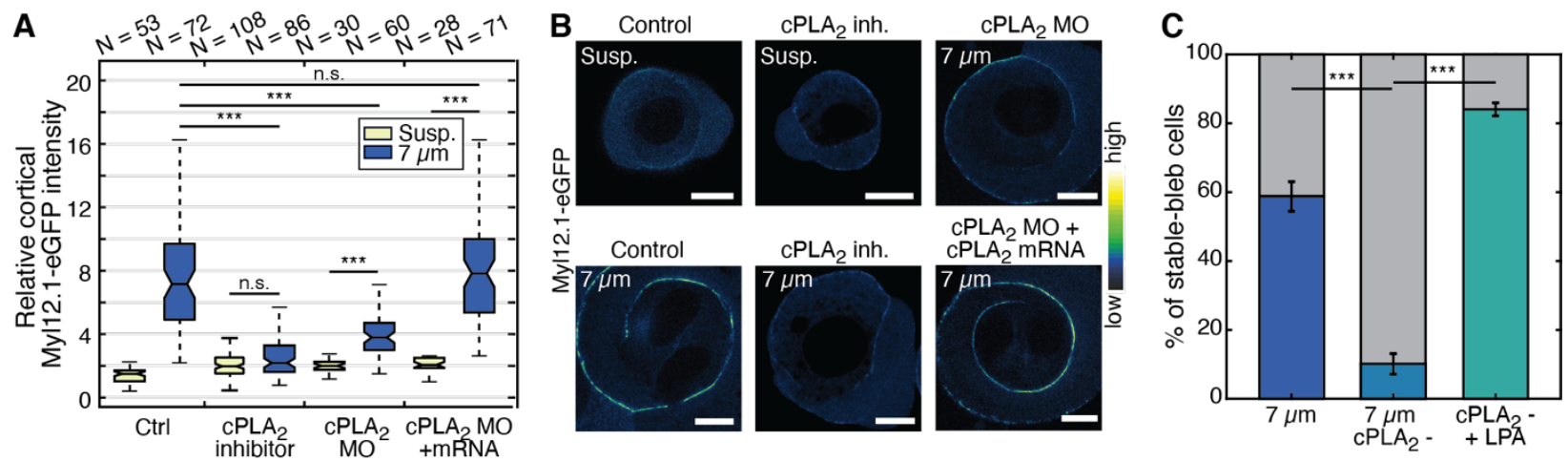

Figure 5. Nucleus deformation activates a mechanosensitive lipase signaling pathway regulating myosin II activity. (A) Relative cortical myosin II intensity for progenitor cells cultured in suspension versus $7 \mu \mathrm{m}$ confinement conditions for control cells (DMEM), with cPLA 2 inhibitor, or injected with cPLA $2 \mathrm{MO}$ and $\mathrm{cPLA}_{2} \mathrm{MO}+\mathrm{cPLA}_{2}$ mRNA. (B) Exemplary confocal images of progenitor cells expressing myosin II-eGFP related to (A) for indicated conditions. (C) Percentage of stable-bleb polarized cells for control cells under $7 \mu \mathrm{m}$ confinement and in the presence of $\mathrm{cPLA}_{2}$ inhibitor or unconfined (suspension) cells stimulated with $50 \mu \mathrm{M}$ LPA. For all conditions $\mathrm{N}>200 .{ }^{* * *} \mathrm{p}<0.0001,{ }^{*} \mathrm{p}<0.001,{ }^{*} \mathrm{p}<0.01$, not significant (n.s.). All scale bars $10 \mu \mathrm{m}$. 
A
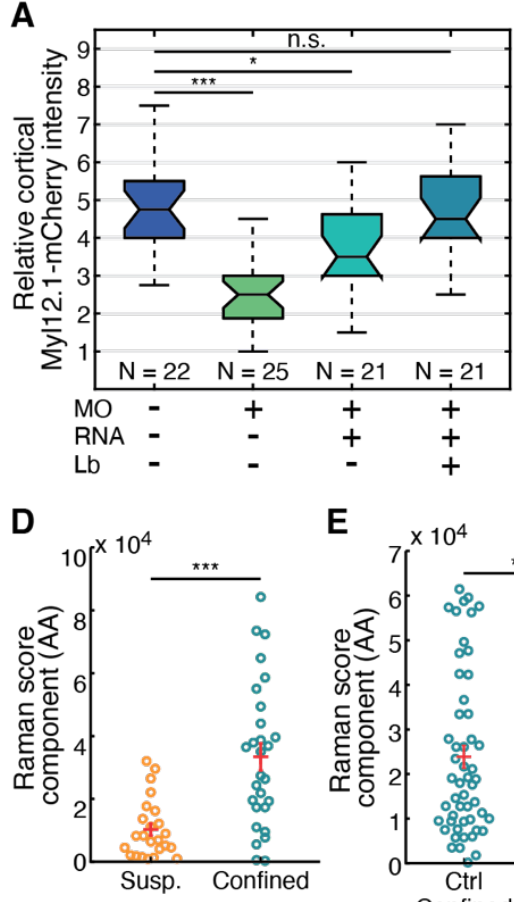

E
B
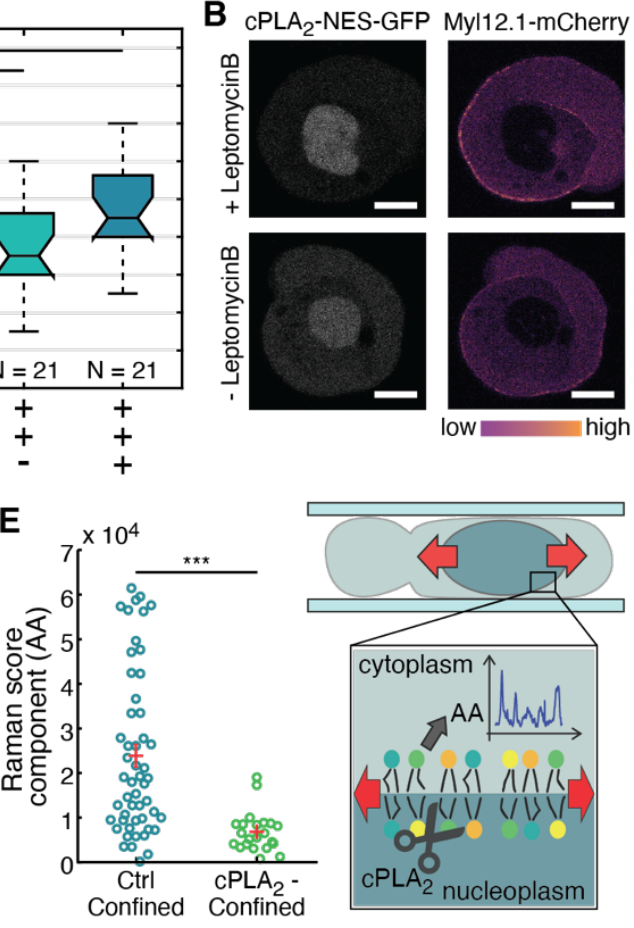

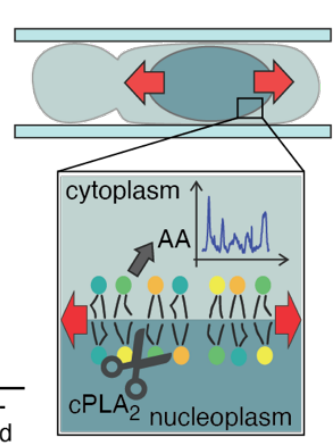

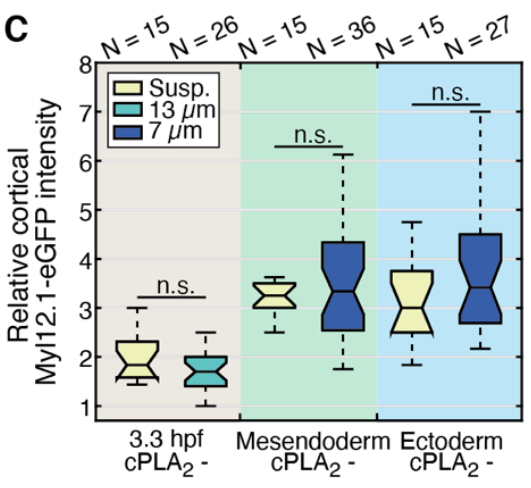

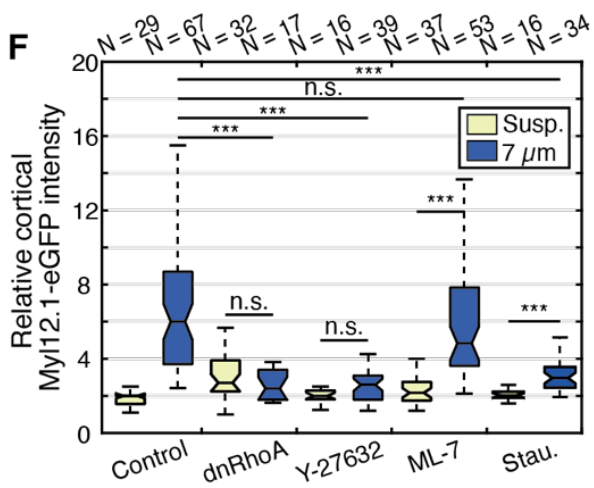

Figure 6. cPLA2 activity at the inner nuclear membrane generates AA as a metabolite regulating cortical contractility in confinement. (A) Relative cortical myosin II fluorescence intensity for cells dissociated from controls (un-injected) embryos or embryos injected with cPLA 2 $\mathrm{MO}, \mathrm{cPLA}_{2} \mathrm{MO}+\mathrm{cPLA}_{2}-\mathrm{NES}-\mathrm{GFP}$ mRNA (RNA) and with or without addition of Leptomycin B (Lb). (B) Exemplary confocal fluorescence images of cell expressing myosin II-mCherry (right) and cPLA 2 -NES-GFP (left) under $7 \mu \mathrm{m}$ confinement with (top) or without (bottom) the addition of Lb. (C) Relative cortical myosin II fluorescence intensity upon cPLA 2 inhibition for cells dissociated at $3.3 \mathrm{hpf}$, induced mesendoderm or ectoderm cells in suspension and upon confinement at indicated height. (D, E) Scores of Raman component associated to AA in suspension (unconfined, $\mathrm{N}=24)$ and confined cells $(10 \mu \mathrm{m}, \mathrm{N}=28)$ and $(\mathrm{H})$ in control confinement condition ( $\mathrm{Ctrl}, \mathrm{N}=52)$ or treated with $\mathrm{cPLA}_{2}$ inhibitor $(\mathrm{N}=22)$. Red lines indicate mean and sem. (F) Relative cortical myosin II intensity for control cells and different chemical (Y-27637, M-L7, 


\section{Science}

Staurosporine) or genetic interference $(\mathrm{dnRhoA})$ with myosin II regulators. $* * * p<0.0001$, $*^{*} \mathrm{p}<0.001,{ }^{*} \mathrm{p}<0.01$, not significant (n.s.). All scale bars $10 \mu \mathrm{m}$. 
A
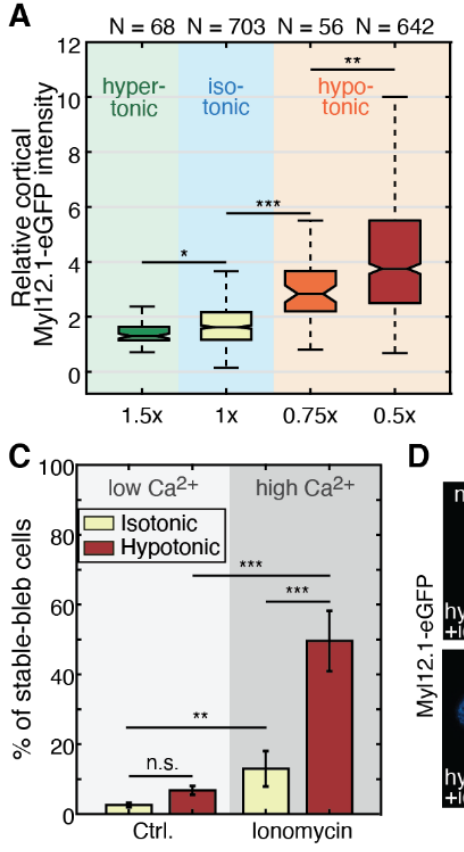

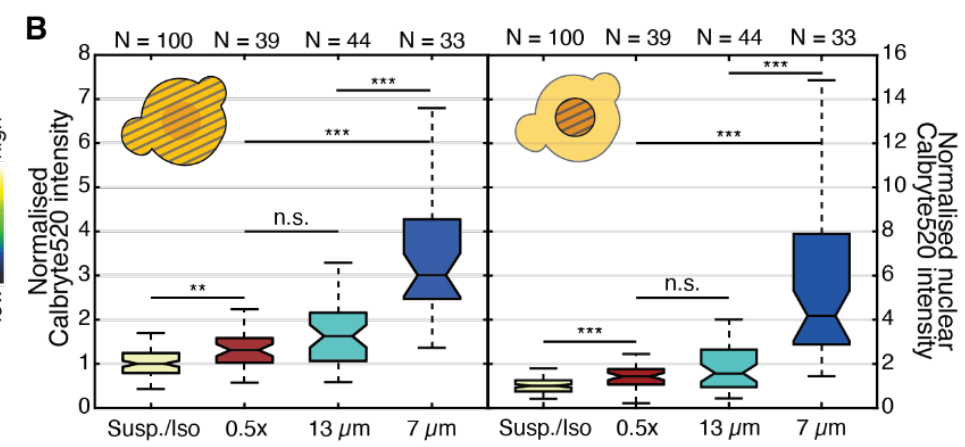

E
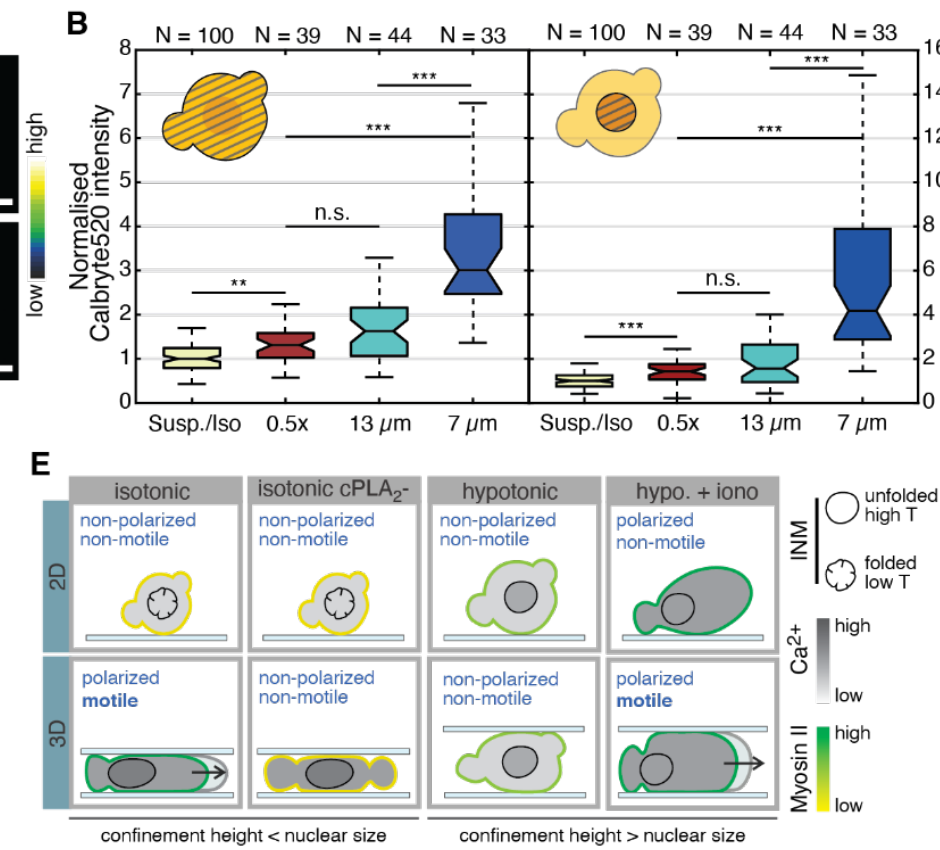

confinement height > nuclear size

Figure 7. Nucleus stretch and intracellular positioning enable an adaptive cellular
response to different types of physical cell deformation. (A) Relative cortical myosin II

Figure 7. Nucleus stretch and intracellular positioning enable an adaptive cellular
response to different types of physical cell deformation. (A) Relative cortical myosin II

D

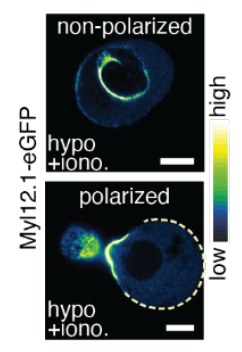
enrichment for progenitor cells cultured under different osmolarity conditions. (B) Normalized cell (left) and nuclear (right) $\mathrm{Ca}^{2+}$ levels (Calbryte520) for control (Ctrl) and hypotonic (0.5 x) conditions and mechanical confinement $(13 \mu \mathrm{m}, 7 \mu \mathrm{m})$. (C) Percentage of stable-bleb polarized cells in isotonic and hypotonic $(0.5 \mathrm{x})$ conditions for cells cultured in DMEM (Ctrl) or supplemented with $1 \mu \mathrm{M}$ ionomycin. $\mathrm{N}>1000$ cells for all conditions. (D) Exemplary confocal 10 images of cells expressing myosin II-eGFP in isotonic (ctrl, top-left), hypotonic (bottom-left) and hypotonic conditions supplemented with ionomycin treatment (right): non-polarized cell (top) and stable-bleb polarized cell (bottom). (E) Sketch of cell polarization and motile cell behavior in 2D (top) versus 3D confined environments (bottom) and for control conditions (isotonic media; first column) versus cPLA $_{2}$ interference (second column) and hypotonic 15 condition alone (third column) or in the presence of ionomycin (fourth column). ${ }^{* * *} \mathrm{p}<0.0001$, ${ }^{* *} \mathrm{p}<0.001,{ }^{*} \mathrm{p}<0.01$, not significant (n.s.). Scale bars $10 \mu \mathrm{m}$. 

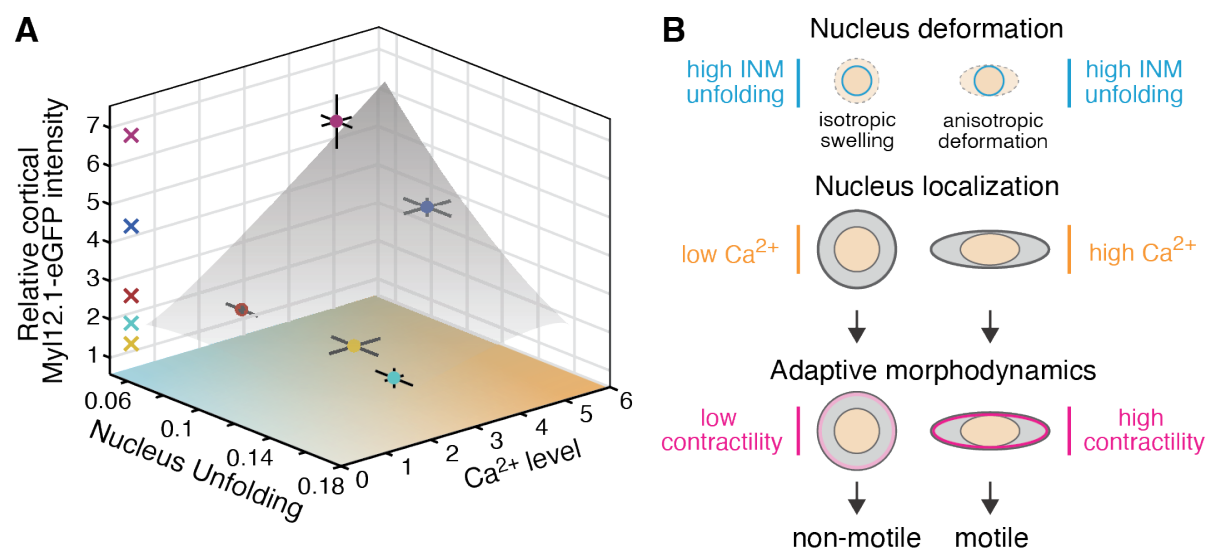

Figure 8. INM unfolding and intracellular calcium levels enable cells to decode isotropic stretch versus cell squeezing in confinement. (A) Normalized relative cortical myosin II fluorescence intensity as a function of nucleus unfolding and normalized $\mathrm{Ca}^{2+}$ (Calbryte) intensity for different physical cell deformations (dark blue: $7 \mu \mathrm{m}$; light blue: $13 \mu \mathrm{m}$ confinement; yellow: $7 \mu \mathrm{m}$ confinement + Bapta-AM; red: hypotonic $(0.5 \mathrm{x})$ condition; magenta: hypotonic condition $(0.5 x)+$ ionomycin $)$. Data indicate mean and sem. The gray area sketches the relation between cortical myosin II and nuclear deformation versus intracellular calcium levels. (N: calcium data related to Fig. 4B, except for hypo + ionomycin $(\mathrm{N}=41)$ and Bapta-AM $+7 \mu \mathrm{m} \mathrm{N}=9$; for nuclear unfolding related to Fig. 2D, Fig S6B and for cortical myosin II levels to Fig. 1A, S5I, 4A, S6F). (B) Sketch depicting how nucleus deformation and intracellular nucleus positioning correlate with INM unfolding and intracellular calcium levels, which differentially regulate cortical contractility and cellular morphodynamics. $* * * p<0.0001$, $* * \mathrm{p}<0.001, * \mathrm{p}<0.01$, not significant (n.s.). Scale bars $10 \mu \mathrm{m}$. 


\section{Materials and Methods}

Zebrafish Maintenance Zebrafish (Danio rerio) were maintained as previously described (75). Embryos were kept in E3 medium at $25^{\circ} \mathrm{C}-31^{\circ} \mathrm{C}$ prior to experiments and staged based on morphological criteria (76) and hours post fertilization (hpf). Wild type embryos were obtained from the AB strain background. All protocols used have been approved by the Institutional Animal Care and Use Ethic Committee (PRBB-IACUEC) and implemented according to national and European regulations. All experiments were carried out in accordance with the principles of the 3Rs.

Transgenic fish lines The following transgenic lines were used: $\operatorname{Tg}$ (actb2:Lifeact-GFP) (77), Tg(actb2:Myl12.1-eGFP) (78), Tg(actb2:Myl12.1-mcherry) (4), Tg(mezzo:eGFP) (23), Tg(actb2:Lyn-TdTomato) (79). All progenitor cells expressing Myl12.1-eGFP (Myosin II) and Lifeact-GFP (Actin) were obtained from Tg(actb2:Myl12.1-eGFP) and Tg(actb2:Lifeact-GFP).

Cell culture To culture progenitor cells, embryos were manually dechorionated in E3 buffer at sphere stage $(4 \mathrm{hpf})$ or different stages if indicated. Five to twenty embryos were transferred to DMEM-F12 (with L-Glut and 15mM HEPES, without sodium bicarbonate and phenol red) culture medium (Sigma) and mechanically dissociated by manual tapping followed by centrifugation at $200 \mathrm{~g}$ for $3 \mathrm{~min}$.

Sample preparation and surface coatings The following products for surface coatings at the indicated concentration have been used: $0.5 \mathrm{mg} / \mathrm{ml}$ PLL(20)-g[3,5]-PEG(2) (Susos) and 0.2 mg/ml fibronectin (Sigma-Aldrich). Prior to PLL-PEG coating, both coverslips and dishes were plasma cleaned. Uncoated or PLL-coated glass dishes \#1.5 were purchased from MatTek (MatTek Corporation).

Cell confiner Cells were confined using a dynamic confiner (4DCell) similar to previously established planar microconfinement methods (30). In order to confine cells at different heights, multiple Si molds were produced by photolithography in a clean room (Nanofabrication laboratory, ICFO) by depositing a SU-8 resin on a silicon wafer. In brief, a photomask with the desired geometry was created. Confinement coverslips were prepared with polydimethylsiloxane (PDMS) with the following heights: 18, 16, 13, 10, 8.5 and $7 \mu \mathrm{m}$. Coverslips were always plasma cleaned, coated with PLL-PEG if not indicated otherwise and equilibrated in DMEM prior to each experiment. A pressure pump (AF1 - Microfluidic pressure pump, Elveflow) together with the ESI software was used to change the pressure for tuning the confinement heights. For Raman measurements and optical tweezers two coverslips separated with microbeads or with a PDMS membrane have been used (height $\mathrm{h}=10 \mu \mathrm{m}$ ).

35 Reagents and inhibitor treatments Pharmacological inhibitors were used at the following concentrations: $1 \mu \mathrm{M}$ cPLA 2 inhibitor (Pyrrophenone, Merck-Millipore), $10 \mu \mathrm{M}$ Bapta-AM (Cayman), $10 \mu \mathrm{M}$ Blebbistatin (+) (Tocris Bioscience), $10 \mu \mathrm{M}$ Y-27632 (Tocris Bioscience), $10 \mu \mathrm{M}$ ML-7 hydrochloride (Tocris Bioscience), $1 \mu \mathrm{M}$ Nocodazole (Sigma), $50 \mathrm{nM}$ LeptomycinB (Sigma-Aldrich), $1 \mu \mathrm{M}$ Ionomycin (Sigma-Aldrich), $1 \mu \mathrm{M}$ Thapsigargin (Thermofisher), $10 \mu \mathrm{M}$ $40 \quad$ GsMTx4 (Tocris), $50 \mu \mathrm{M}$ 2-APB (Biogen-Santa Cruz), $10 \mu \mathrm{M}$ Gadolinium chloride (Tocris), $2 \mu \mathrm{M}$ Actinomycin D (PanReac), $100 \mu \mathrm{M}$ Z-VAD(OMe)-FMK (Abcam), $1 \mu \mathrm{M}$ Staurosporine (Abcam), 1-oleoyl lysophosphatidic acid (LPA, Tocris Bioscience) was used at the indicated concentrations. Measurements were done directly after exposure to MLCK inhibitor, GsMTx4, Ionomycin, LPA; all the other inhibitors have been pre-incubated for 30 min and 60 min for Y27632 prior to experiments. 


\section{Science}

Fluorescence staining Calbryte520 (AAT BIOQUEST) was used to study calcium dynamics. The staining kit-Red Fluorescence-Cytopainter (ER Tracker, Abcam) or ER-Tracker ${ }^{\mathrm{TM}}$ Green (BODIPYTM FL Glibenclamide) were used to visualize the endoplasmic reticulum respectively for confocal 3D colors imaging and for TIRF microscopy experiment. DNA-Hoechst (Thermofisher) was used to stain the cell nucleus. Cells were incubated with $5 \mu \mathrm{M}$ Calbryte 520 for 20 min, with $1 \mu \mathrm{M}$ ER-tracker for $30 \mathrm{~min}$ and with $1 \mu \mathrm{g} / \mathrm{ml}$ DNA-Hoechst for 7-10 min as reported in the corresponding protocols. After incubation, cells were washed, centrifuged at $200 \mathrm{~g}$ for $3 \mathrm{~min}$ and re-suspended in DMEM media.

Variable osmotic culture conditions D-Mannitol (Sigma) was diluted in DMEM in order to obtain a culture medium with an osmolarity of approx. $450 \mathrm{mOsm} / 1$ (corresponding to a $1.5 \mathrm{x}$ media). Milli-Q water was added to DMEM for hypotonic conditions. 


\section{References}

1. G. Salbreux, G. Charras, E. Paluch, Actin cortex mechanics and cellular morphogenesis. Trends Cell Biol 22, 536-545 (2012).

2. N. W. Goehring, S. W. Grill, Cell polarity: mechanochemical patterning. Trends Cell Biol 23, 72-80 (2013).

3. A. C. Callan-Jones, R. Voituriez, Actin flows in cell migration: from locomotion and polarity to trajectories. Curr Opin Cell Biol 38, 12-17 (2016).

4. M. Vicente-Manzanares, X. Ma, R. S. Adelstein, A. R. Horwitz, Non-muscle myosin II takes centre stage in cell adhesion and migration. Nat Rev Mol Cell Biol 10, 778-790 (2009).

5. M. A. Wozniak, C. S. Chen, Mechanotransduction in development: a growing role for contractility. Nat Rev Mol Cell Biol 10, 34-43 (2009).

6. T. Lecuit, P. F. Lenne, E. Munro, Force generation, transmission, and integration during cell and tissue morphogenesis. Annu Rev Cell Dev Biol 27, 157-184 (2011).

7. E. M. Balzer et al., Physical confinement alters tumor cell adhesion and migration phenotypes. FASEB J 26, 4045-4056 (2012).

8. K. J. Sonnemann, W. M. Bement, Wound repair: toward understanding and integration of single-cell and multicellular wound responses. Annu Rev Cell Dev Biol 27, 237-263 (2011).

9. J. Briscoe, S. Small, Morphogen rules: design principles of gradient-mediated embryo patterning. Development 142, 3996-4009 (2015).

10. G. Charras, E. Sahai, Physical influences of the extracellular environment on cell migration. Nat Rev Mol Cell Biol 15, 813-824 (2014).

11. P. Roca-Cusachs, R. Sunyer, X. Trepat, Mechanical guidance of cell migration: lessons from chemotaxis. Curr Opin Cell Biol 25, 543-549 (2013).

12. M. Duda et al., Polarization of Myosin II Refines Tissue Material Properties to Buffer Mechanical Stress. Developmental Cell 48, 245-260.e247 (2019).

13. A. Sumi et al., Adherens Junction Length during Tissue Contraction Is Controlled by the Mechanosensitive Activity of Actomyosin and Junctional Recycling. Dev Cell 47, 453463 e453 (2018).

14. J. Aureille et al., Nuclear envelope deformation controls cell cycle progression in response to mechanical force. EMBO Rep 20, e48084 (2019).

15. S. A. Gudipaty et al., Mechanical stretch triggers rapid epithelial cell division through Piezo1. Nature 543, 118-121 (2017).

16. E. Marinari et al., Live-cell delamination counterbalances epithelial growth to limit tissue overcrowding. Nature 484, 542-545 (2012).

17. G. T. Eisenhoffer et al., Crowding induces live cell extrusion to maintain homeostatic cell numbers in epithelia. Nature 484, 546-549 (2012).

18. M. Georgouli et al., Regional Activation of Myosin II in Cancer Cells Drives Tumor Progression via a Secretory Cross-Talk with the Immune Microenvironment. Cell, (2019).

19. J. H. Kim et al., Mechanical tension drives cell membrane fusion. Dev Cell 32, 561-573 (2015).

20. T. Luo, K. Mohan, P. A. Iglesias, D. N. Robinson, Molecular mechanisms of cellular mechanosensing. Nat Mater 12, 1064-1071 (2013). 
21. C. J. Cattin et al., Mechanical control of mitotic progression in single animal cells. Proc Natl Acad Sci US A 112, 11258-11263 (2015).

22. T. Lämmermann, M. Sixt, Mechanical modes of 'amoeboid' cell migration. Current opinion in cell biology 21, 636-644 (2009).

23. V. Ruprecht et al., Cortical contractility triggers a stochastic switch to fast amoeboid cell motility. Cell 160, 673-685 (2015).

24. J. S. Logue et al., Erk regulation of actin capping and bundling by Eps8 promotes cortex tension and leader bleb-based migration. Elife 4, e08314 (2015).

25. A. W. Holle et al., Cancer Cells Invade Confined Microchannels via a Self-Directed Mesenchymal-to-Amoeboid Transition. Nano Lett 19, 2280-2290 (2019).

26. T. Brunet, M. Albert, W. Roman, D. C. Spitzer, N. King, (2020).

27. M. Ibo, V. Srivastava, D. N. Robinson, Z. R. Gagnon, Cell Blebbing in Confined Microfluidic Environments. PLoS One 11, e0163866 (2016).

28. Y. J. Liu et al., Confinement and low adhesion induce fast amoeboid migration of slow mesenchymal cells. Cell 160, 659-672 (2015).

29. R. Zhao et al., Cell sensing and decision-making in confinement: The role of TRPM7 in a tug of war between hydraulic pressure and cross-sectional area. Sci Adv 5, eaaw 7243 (2019).

30. M. Le Berre, E. Zlotek-Zlotkiewicz, D. Bonazzi, F. Lautenschlaeger, M. Piel, Methods for two-dimensional cell confinement. Methods Cell Biol 121, 213-229 (2014).

31. M. Bergert et al., Force transmission during adhesion-independent migration. Nat Cell Biol 17, 524-529 (2015).

32. M. Krieg et al., Tensile forces govern germ-layer organization in zebrafish. Nat Cell Biol 10, 429-436 (2008).

33. L. Solnica-Krezel, D. S. Sepich, Gastrulation: making and shaping germ layers. Annu Rev Cell Dev Biol 28, 687-717 (2012).

34. A. D. Bershadsky, N. Q. Balaban, B. Geiger, Adhesion-dependent cell mechanosensitivity. Annu Rev Cell Dev Biol 19, 677-695 (2003).

35. A. Saha et al., Determining Physical Properties of the Cell Cortex. Biophys J 110, 14211429 (2016).

36. W. C. Hung et al., Confinement Sensing and Signal Optimization via Piezo1/PKA and Myosin II Pathways. Cell Rep 15, 1430-1441 (2016).

37. N. I. Petridou, S. Grigolon, G. Salbreux, E. Hannezo, C. P. Heisenberg, Fluidizationmediated tissue spreading by mitotic cell rounding and non-canonical Wnt signalling. Nat Cell Biol 21, 169-178 (2019).

38. K. N. Dahl, S. M. Kahn, K. L. Wilson, D. E. Discher, The nuclear envelope lamina network has elasticity and a compressibility limit suggestive of a molecular shock absorber. J Cell Sci 117, 4779-4786 (2004).

39. B. Enyedi, M. Jelcic, P. Niethammer, The Cell Nucleus Serves as a Mechanotransducer of Tissue Damage-Induced Inflammation. Cell 165, 1160-1170 (2016).

40. E. A. Dennis, J. Cao, Y. H. Hsu, V. Magrioti, G. Kokotos, Phospholipase A2 enzymes: physical structure, biological function, disease implication, chemical inhibition, and therapeutic intervention. Chem Rev 111, 6130-6185 (2011).

41. T. Katayama et al., Stimulatory effects of arachidonic acid on myosin ATPase activity and contraction of smooth muscle via myosin motor domain. Am J Physiol Heart Circ Physiol 298, H505-514 (2010). 
42. M. Brown, J. A. Roulson, C. A. Hart, T. Tawadros, N. W. Clarke, Arachidonic acid induction of Rho-mediated transendothelial migration in prostate cancer. $\mathrm{Br} J$ Cancer 110, 2099-2108 (2014).

43. L. Sun, R. D. Ye, Role of G protein-coupled receptors in inflammation. Acta Pharmacol Sin 33, 342-350 (2012).

44. M. Peters-Golden, K. Song, T. Marshall, T. Brock, Translocation of cytosolic phospholipase A2 to the nuclear envelope elicits topographically localized phospholipid hydrolysis. Biochem J 318 ( Pt 3), 797-803 (1996).

45. A. Dessen et al., Crystal structure of human cytosolic phospholipase A2 reveals a novel topology and catalytic mechanism. Cell 97, 349-360 (1999).

46. J. E. Burke, E. A. Dennis, Phospholipase A2 biochemistry. Cardiovasc Drugs Ther 23, 49-59 (2009).

47. A. Gallo, C. Vannier, T. Galli, Endoplasmic Reticulum-Plasma Membrane Associations:Structures and Functions. Annu Rev Cell Dev Biol 32, 279-301 (2016).

48. S. Carrasco, T. Meyer, STIM proteins and the endoplasmic reticulum-plasma membrane junctions. Annu Rev Biochem 80, 973-1000 (2011).

49. X. Qin et al., Increased Confinement and Polydispersity of STIM1 and Orai1 after $\mathrm{Ca}(2+)$ Store Depletion. Biophys J 118, 70-84 (2020).

50. R. Das, S. Wieser, M. Krieg, Neuronal stretch reception - Making sense of the mechanosense. Exp Cell Res 378, 104-112 (2019).

51. T. J. Kirby, J. Lammerding, Emerging views of the nucleus as a cellular mechanosensor. Nat Cell Biol 20, 373-381 (2018).

52. Z. Jahed, M. R. Mofrad, The nucleus feels the force, LINCed in or not! Curr Opin Cell Biol 58, 114-119 (2019).

53. C. S. Janota, F. J. Calero-Cuenca, E. R. Gomes, The role of the cell nucleus in mechanotransduction. Curr Opin Cell Biol 63, 204-211 (2020).

54. R. P. Martins, J. D. Finan, F. Guilak, D. A. Lee, Mechanical regulation of nuclear structure and function. Annu Rev Biomed Eng 14, 431-455 (2012).

55. Y. Xia, C. R. Pfeifer, S. Cho, D. E. Discher, J. Irianto, Nuclear mechanosensing. Emerg Top Life Sci 2, 713-725 (2018).

56. A. Elosegui-Artola et al., Force Triggers YAP Nuclear Entry by Regulating Transport across Nuclear Pores. Cell, (2017).

57. J. Swift et al., Nuclear Lamin-A Scales with Tissue Stiffness and Enhances MatrixDirected Differentiation. Science (New York, N.Y.) 341, 1240104-1240104 (2013).

58. M. Almonacid, M. E. Terret, M. H. Verlhac, Nuclear positioning as an integrator of cell fate. Curr Opin Cell Biol 56, 122-129 (2019).

59. K. Damodaran et al., Compressive force induces reversible chromatin condensation and cell geometry dependent transcriptional response. Mol Biol Cell, mbcE18040256 (2018).

60. A. Kumar et al., ATR mediates a checkpoint at the nuclear envelope in response to mechanical stress. Cell 158, 633-646 (2014).

61. M. M. Nava et al., Heterochromatin-Driven Nuclear Softening Protects the Genome against Mechanical Stress-Induced Damage. Cell, (2020).

62. A. L. McGregor, C.-R. Hsia, J. Lammerding, Squish and squeeze - the nucleus as a physical barrier during migration in confined environments. Current Opinion in Cell Biology 40, 32-40 (2016). 
63. R. Majumdar, K. Steen, P. A. Coulombe, C. A. Parent, Non-canonical processes that shape the cell migration landscape. Curr Opin Cell Biol 57, 123-134 (2019).

64. R. J. Petrie, H. Koo, K. M. Yamada, Generation of compartmentalized pressure by a nuclear piston governs cell motility in a 3D matrix. Science 345, 1062-1065 (2014).

65. C. M. Denais et al., Nuclear envelope rupture and repair during cancer cell migration. Science 352, 353-358 (2016).

66. M. Raab et al., ESCRT III repairs nuclear envelope ruptures during cell migration to limit DNA damage and cell death. Science 352, 359-362 (2016).

67. J. Renkawitz et al., Nuclear positioning facilitates amoeboid migration along the path of east resistance. Nature 568, 546-550 (2019).

68. A. J. Lomakin et al., (2019).

69. S. van Helvert, C. Storm, P. Friedl, Mechanoreciprocity in cell migration. Nat Cell Biol 20, 8-20 (2018).

70. H. D. Moreau, M. Piel, R. Voituriez, A. M. Lennon-Dumenil, Integrating Physical and Molecular Insights on Immune Cell Migration. Trends Immunol 39, 632-643 (2018).

71. V. Te Boekhorst, L. Preziosi, P. Friedl, Plasticity of Cell Migration In Vivo and In Silico. Annu Rev Cell Dev Biol 32, 491-526 (2016).

72. D. Wirtz, K. Konstantopoulos, P. C. Searson, The physics of cancer: the role of physical interactions and mechanical forces in metastasis. Nat Rev Cancer 11, 512-522 (2011).

73. E. Hannezo, C.-P. Heisenberg, Mechanochemical Feedback Loops in Development and Disease. Cell 178, 12-25 (2019).

74. S. A. Gudipaty, J. Rosenblatt, Epithelial cell extrusion: Pathways and pathologies. Semin Cell Dev Biol 67, 132-140 (2017).

75. W. Westerfield, The zebrafish book: a guide for the laboratory use of zebrafish (Brachydanio rerio). (1995).

76. C. B. Kimmel, W. W. Ballard, S. R. Kimmel, B. Ullmann, T. F. Schilling, Stages of embryonic development of the zebrafish. Dev Dyn 203, 253-310 (1995).

77. M. Behrndt et al., Forces driving epithelial spreading in zebrafish gastrulation. Science 338, 257-260 (2012).

78. J. L. Maitre et al., Adhesion functions in cell sorting by mechanically coupling the cortices of adhering cells. Science 338, 253-256 (2012).

79. J. Compagnon et al., The notochord breaks bilateral symmetry by controlling cell shapes in the zebrafish laterality organ. Dev Cell 31, 774-783 (2014). 


\section{Science MIAAAS}

\section{Supplementary Materials for}

\section{The nucleus measures shape changes for cellular proprioception to control dynamic cell behavior}

Authors: Valeria Venturini, Fabio Pezzano, Frederic Català Castro, Hanna-Maria Häkkinen, Senda Jiménez-Delgado, Mariona Colomer-Rosell, Mónica Marro, Queralt Tolosa-Ramon, Sonia Paz-López, Miguel A. Valverde, Julian Weghuber, Pablo Loza-Alvarez, Michael Krieg, Stefan Wieser*, Verena Ruprecht*

* Correspondence to stefan.wieser@icfo.eu and verena.ruprecht@crg.eu

This PDF file includes:

Supplementary Methods

Figures. S1 to S7

Supplementary Table S1.

Captions for Movies S1 to S9

Supplementary References

Other Supplementary Materials for this manuscript include the following:

Movies S1 to S9 


\section{Supplementary Methods}

Plasmid cloning The following constructs were subcloned in a pCS2+ or pCS2+-eGFP vector, linearized with BamHI-EcoRI restriction enzymes, using the Gibson cloning system: LAP2beGFP was amplified from a pME 18S-FL3 vector (clone \#2643665, Dharmacon); cPLA2a (pla2g4aa) plasmid was amplified from a pCR4-TOPO vector (clone \#9037889, Dharmacon). Human STIM and Orai were subcloned from mCFP-N1 and mYFP-N1 plasmids (80), respectively, into a pCS2+ vector and linearized with EcoRI-XbaI restriction enzymes. All cDNAs were amplified using Phusion HF DNA Polymerase (Thermofisher F530S), see primers below. NES-cPLA2a-eGFP was amplified from the pCS2+-cPLA2a-eGFP vector using primers encoding for an N-terminal NES sequence (LPPLERLTL). The following constructs were provided from different labs: pCS2-DNRhoA N19 (81); pCS2+_cyclops (82), pCS2+ lefty and Casanova (courtesy Carl-Philipp Heisenberg); pCS2+ Lyn-TdTomato (courtesy Berta Alsina); pTriEx-RhoA FLARE.sc Biosensor WT was a gift from Klaus Hahn (Addgene plasmid \#12150; RRID:Addgene_12150).

Oligonucleotides used for cloning:

\begin{tabular}{|c|c|}
\hline pCS2-LAP2b-eGFP Fw 1 & $\begin{array}{l}\text { 5'- } \\
\text { GCTACTTGTTCTTTTTGGAGGATCCATGTCGGAATTTCTGGAAGAC } \\
\text { CC-3' }\end{array}$ \\
\hline pCS2-LAP2b-eGFP Rv 1 & 5'-CTATTGAGGGCTCAGAGAAATCCTTGT-3' \\
\hline pCS2-LAP2b-eGFP Fw 2 & 5'-TTTCTCTGAGCCCTCAATAGTGAAGGAG-3' \\
\hline pCS2-LAP2b-eGFP Rv 2 & $\begin{array}{l}\text { 5'- } \\
\text { CCTCGCCCTTGCTCACCATGAATTCTTTGCTGGTACTGTCATCTGTG } \\
\text { CC-3' }\end{array}$ \\
\hline pCS2-cPLA2a Fw & $\begin{array}{l}\text { 5'- } \\
\text { GCTACTTGTTCTTTTTGCAGGATCCGCCACCATGTCCAACATTATAG } \\
\text { TAAGTGACGCTTG-3' }\end{array}$ \\
\hline pCS2-cPLA2a Rv & $\begin{array}{l}\text { 5'- }^{\prime} \\
\text { GCTCGAGAGGCCTTGAATTCTCACACTTTTGTGTAGCTTTTTGCA-3' }\end{array}$ \\
\hline pCS2_NES-cPLA2a-eGFP Fw & $\begin{array}{l}\text { 5'- } \\
\text { GCTACTTGTTCTTTTTGCAGGATCCGCCACCATGCTGCCCCCCCTGG } \\
\text { AGCGCCTGACCCTGTCCAACATTATAGTTG -3' }\end{array}$ \\
\hline pCS2_NES-cPLA2a-eGFP Rv & 5'- GCTCGAGAGGCCTTGAATTCCTAGAgCTTGTACAGCTCGTCC-3' \\
\hline pCS2-cPLA2a-eGFP Fw & $\begin{array}{l}\text { 5'- } \\
\text { GCTACTTGTTCTTTTTTGCAGGATCCATGTCCAACATTATAGTTGAGC } \\
\text { ATCAGTATTCT-3' }\end{array}$ \\
\hline pCS2-cPLA2a-eGFP Rv & $\begin{array}{l}\text { 5'- } \\
\text { CCTCGCCCTTGCTCACCATGAATTCGGTGGGTCGTTTTTGCAATGC- } \\
3^{\prime}\end{array}$ \\
\hline
\end{tabular}




\begin{tabular}{|l|l|}
\hline pCS2-StimCFP Fw & 5'- \\
& AGGATCCCATCGATTCGAATTCGCCACCATGGATGTATGCGTCCGT \\
& CTTG-3' \\
\hline pCS2-StimCFP Rv & 5'- \\
& CGTAATACGACTCACTATAGTTCTAGATTACTTGTACAGCTCGTCCA \\
& TGCC-3' \\
\hline pCS2-OraiYFP Fw & $\begin{array}{l}\text { '- } \\
\text { AGGATCCCATCGATTCGAATTCGCCACCATGCATCCGGAGCCCG-3' }\end{array}$ \\
\hline pCS2-OraiYFP Rv & 5 - \\
& 'CGTAATACGACTCACTATAGTTCTAGATTACTTGTACAGCTCGTCC \\
& ATGCC-3' \\
\hline
\end{tabular}

Zebrafish mRNA injections mRNA was synthesized using the mMessage mMachine Kit SP6 Kit (Ambion AM1340M). All mRNA injections were done in 1-cell stage embryos. To visualize the inner nuclear membrane (INM) 80 pg of Lap2B-eGFP were injected into wild type AB or Tg(actb2:Lyn-TdTomato) embryos. To interfere with myosin II regulators $100 \mathrm{pg}$ of dn-RhoA mRNA (81) have been injected in $\mathrm{Tg}(\mathrm{actb} 2$ :Myl12.1-eGFP) embryos together with $100 \mathrm{pg}$ LynTomato mRNA (to visualize plasma membrane). For RhoA-Fret imaging $400 \mathrm{pg}$ of RhoABiosensor (83) were injected in wild type embryos. To induce mesendoderm, endoderm, mesoderm or ectoderm cells, 1-cell stage wild type or Tg(actb2:Myl12.1-eGFP) embryos were injected respectively with: 100 pg cyclops mRNA, 50 pg Casanova mRNA, 100 pg cyclops mRNA and 2 ng Casanova morpholino (GCATCCGGTCGAGATACATGCTGTT), 100 pg Lefty mRNA, all supplemented with $100 \mathrm{pg}$ LynTomato mRNA. To visualize $\mathrm{cPLA}_{2}$ localization $50 \mathrm{pg}$ of cPLA $_{2}$-eGFP mRNA were injected into 1-cell stage wild type or Tg(actb2:My112.1-mCherry) embryos. To visualize the STIM-Orai complex $80 \mathrm{pg}$ of STIM-CFP together with $50 \mathrm{pg}$ of OraiYFP mRNA were injected into 1-cell stage wild type embryos.

Morpholino interference and rescue experiments For inhibiting cPLA 2 activity, $2.7 \mathrm{ng}$ of cPLA $_{2}$ morpholino (AAGCGTCACTTACTATAATGTTGGA) were injected in 1-cell stage Tg(actb2:Myl12.1-eGFP) or Tg(actb2:Myl12.1-mcherry) embryos. To rescue the activity, cPLA 2 morpholino was co-injected with $200 \mathrm{pg}$ of cPLA 2 mRNA and $100 \mathrm{pg}$ of LynTomato mRNA or $200 \mathrm{pg}$ of NES-cPLA 2 -GFP mRNA. The same concentrations of mRNA were used for control experiments.

Zebrafish blastula injections For injection of hypotonic media, Zebrafish embryos at sphere stage were dechorionated and placed in single embryo agarose wells (Adaptive Science Tools). Injections were applied into the extracellular space at the animal pole. Each embryo was injected with an average of $16 \mathrm{nl}$ of injection mix containing hypotonic media (D3:MilliQ 1:1) with Dextran and Alexa Fluor ${ }^{\mathrm{TM}} 546$ (10 kMW, Anionic,ThermoFisher Scientific) to label the interstitial fluid and together with $10 \mu \mathrm{M}$ Ionomycin calcium salt (Sigma-Aldrich).

Embryo mounting: Embryos were mounted in 2\% low melting point agarose prepared in Danieau's solution (58 mM NaCl, 0.7 mM KCl, $0.4 \mathrm{mM} \mathrm{MgSO} 4,0.6 \mathrm{mM} \mathrm{Ca(NO3)2}$ and $5 \mathrm{mM}$ HEPES) on a Mattek dish and covered with Danieau's solution.

Fluorescence imaging Confocal fluorescence images were acquired using a commercial Leica TCS SP5 STED CW or Leica TCS SP8 STED 3X microscope equipped with a white light laser source (Leica Microsystems, Wetzlar, Germany). In both cases we used a 63x oil objective 
(NA=1.49, HCX PL APO CS 63.0x1.40 oil UV). For myosin II-eGFP, LifeACT-eGFP, Lap2BeGFP and Calbryte520 AM, cPLA 2 -NES-GFP imaging, samples were excited with a $488 \mathrm{~nm}$ Argon laser using the SP5 microscope. For co-staining with the Lyn-Tomato membrane reporter or for myosin II-mCherry experiments, a HeNe laser at $543 \mathrm{~nm}$ has been used for excitation and consecutives images have been acquired. In both color channels fluorescence was collected using single molecule detectors (SMD-HyD) in photon counting mode and transmission light was collected using a forward PMT. The Leica SP8 confocal microscope has been used for three color imaging. Myosin II-GFP and ER-tracker Red have been excited respectively at $488 \mathrm{~nm}$ and $587 \mathrm{~nm}$ using a tuneable white light laser. The fluorescence light was collected using two backwards HyD detectors in photon counting mode while the DNA-Hoechst has been excited with a $405 \mathrm{~nm}$ semiconductor laser and fluorescence recorded using a PMT. The same microscope was used for FRET imaging: the CFP was excited with the 405nm laser and the YFP at $512 \mathrm{~nm}$ using the white light laser and the emitted photons have been collected using the HyD detector in photon counting modes. Transmission light was collected using a forward PMT. For time-lapse movies related to Fig. S2A and Supplementary Movie S3, a 40X oil objective (NA=1.25, HCX PL APO) was used and myosin II-eGFP samples were excited with a $488 \mathrm{~nm}$ Argon laser and fluorescent intensity recorded with a SMD-HyD detector in standard mode using the SP5 microscope. A temperature controller set at $\mathrm{T}=28.5^{\circ} \mathrm{C}$ was used for all experiments.

In vivo confocal imaging Embryos were imaged using a Leica SP5 confocal microscope equipped with a Leica 20X NA 0.7 immersion objective using a $488 \mathrm{~nm}$ laser and the emitted fluorescence was detected with a HyD detector. The temperature during imaging was kept constant at $28.5^{\circ} \mathrm{C}$ using a temperature chamber.

Bright field imaging Bright field movies were acquired using a Leica DMI-LED microscope equipped with IDS-CMOS cameras (UI-3880LE-M-GL) and a Leica 0.4x C-mount. Air objectives $10 \mathrm{x}(\mathrm{NA}=0.25)$ or $20 \mathrm{x}(\mathrm{NA}=0.40)$ were used to image cell dynamics. Acquisition was controlled using $\mu$ Manager (84).

TIRF imaging (related to Supplementary Movie 9) Images were acquired using a custom-built TIRF microscope equipped with an Andor Zyla 4.2 cMOS camera and a UPLAPO100XOHR objective. ER-tracker Green was excited with a $473 \mathrm{~nm}$ GEM laser by Laser Quantum using an exposure time of $0.5 \mathrm{~s}$.

Optical trapping experiments The optical tweezer (OT) platform (SensoCell, Impetux Optics, Spain) consists of a continuous wave laser ( $\lambda=1064 \mathrm{~nm}, 5 \mathrm{~W}$ nominal output power, Azur Light) steered with a pair of acousto-optic deflectors (AOD) and a force detection unit that captures the forward-scattered light from the optical traps. This is mounted around an inverted research microscope (Nikon Eclipse Ti2) equipped with a spinning disk confocal microscope (Andor DragonFly 502) on top of an active isolation table (Newport). The laser is directed onto a microscope objective (MO, 60x/NA=1.2, water immersion, Nikon) after being expanded with a telescope to fill the MO entrance pupil through the epi-fluorescence port. A short-pass dichroic mirror reflects the IR trapping beam and transmits both the excitation and emission light for fluorescence microscopy, as well as bright-field.

The force detection unit of our optical tweezers platform operates by detecting light-momentum changes, after capturing the scattered trapping beam through an NA $=1.4$, oil immersion lens, with a position-sensitive detector (PSD) placed at the back focal plane (BFP) (85). This allowed us to measure forces beyond the linear trapping regime, thus covering the full spectrum until $\sim 300 \mathrm{pN}$ and enabling to work with lower laser powers during intracellular force measurements, as 
compared to standard BFP interferometry (85). To perform intracellular trapping, we injected a $0.5 \mathrm{~nL}$ drop of diluted (1:5) $1 \mu \mathrm{m}$ polystyrene beads (Sigma-Aldrich) into 1-cell stage embryos. Cells were seeded in homemade trapping microchambers consisting of a bottom-dish (Wilco Glass, \#1.5) and a $1 \times 1$ inch cover glass spaced with a double scotch, $90 \mu \mathrm{m}$ high tape. The bottom dish was coated with Concanavalin A $(0.05 \mathrm{mg} / \mathrm{ml}, 30 \mathrm{~min}$, Sigma-Aldrich) to partially adhere the cells and avoid movement due to cellular blebbing. For the optical trapping experiments in confinement conditions, we used two cover glasses $(60 \times 24 \mathrm{~cm}$, \# 1.5, Ted Pella) to enclose a few $\mu \mathrm{l}$ of cells and $10 \mu \mathrm{m}$ PS beads used as spacers. Only non-polarized cells containing one bead were used for each measurement. The bead was trapped by manually directing the focused laser beam on it, at $300 \mathrm{~mW}$ power (at the sample plane; $2.5 \mathrm{~W}$ output power) and was then brought against the nuclear membrane. Trap positioning and force measurements were carried out by addressing the AODs in synchronization with the PSD with the OT platform software (LightAce, Impetux Optics, Spain), based on LabView (National Instruments). This software allows us to perform custom trap trajectories for our nucleus indentation tests while detecting force (Fig. S4 D,E).

After fast indentation perpendicular to the nuclear membrane $(\sim 2-3 \mu \mathrm{m})$, the trap position was kept constant for $10 \mathrm{~s}$. The same was applied with no bead to account for initial momentum changes arising from dynamic trap location. Upon indentation, an elastic increase in force was followed by a force relaxation that was fitted by the following expression: $f(t)=A+(B-A) t^{-p} e^{-t / \tau}$; where $\mathrm{A}[\mathrm{pN}]$ is the static force given by the residual stress applied onto the nuclear membrane; $\mathrm{B}$ $[\mathrm{pN}]$ is the peak force; $\mathrm{p}$ is the exponent for the initial, short time scale power law decay; and $\tau$ [s] is the characteristic time for the exponential decay at longer time scale. $\tau$ agreed to that obtained from a linear fit onto the data plot at semi-logarithmic scale, as $\tau=-1 / m$, where $m$ is the slope of the fitted line. Normalized force relaxation profiles (Suppl. Fig. S4 F,G) were obtained by scaling the force as $(f(t)-A) /(B-A)$. $\tau$ and $\mathrm{B}$ were obtained for $\mathrm{N}=21$ cells in suspension and $\mathrm{N}=15$ cells under mechanical confinement (Fig. S4 H,I). Data were processed with customwritten Matlab scripts.

Nuclear deformation was imaged during the trapping routine using a Nipkow spinning-disk confocal imaging platform (Andor DragonFly 502). To block reflections from the trapping laser light, an IR filter was placed in the beam path of the microscope. Nuclear DNA was stained after incubation for 5-10 min in 5 $\mu \mathrm{g} / \mu \mathrm{l}$ Hoechst dye and cells were excited with $\lambda=405 \mathrm{~nm}$ (DNAHoechst staining) and $\lambda=488 \mathrm{~nm}$ (myosin II-eGFP). The two laser lines were transmitted through a multi-band dichroic (405-488-561-637 nm, AHF) to simultaneously excite the two fluorophores in the sample. After emission, light is directed into a long-pass dichroic $(500 \mathrm{~nm})$, which enables parallel imaging of the two channels using two back-illuminated sCMOS cameras (Sona, Andor) after passing through emission filters $445 / 46 \mathrm{~nm}$ and $521 / 38 \mathrm{~nm}$, respectively. Image acquisition was performed using Fusion Software and post-processed in Fiji. Tracking of nuclear morphodynamics was carried out by fitting a double sigmoid function over the segment along the indentation direction with a custom written analysis script.

Raman spectroscopy (RS) For RS experiments, progenitor cells dissociated from wild type embryos at sphere stage were used and measurements were carried out using re-suspending cells in DMEM media solution. For confinement conditions, a drop of cells was placed between two quartz coverslips (ESCO products, Oak Ridge, NJ). For non-confined cells, a separation of around $100 \mu \mathrm{m}$ was left between the two coverslips. A total of minimum 25 spectra were obtained from different non-polarized cells for each condition in the cytoplasm or nucleus. The Raman system 
(inVia Renishaw, Apply Innovation, Gloucestershire, U.K.) comprises a $532 \mathrm{~nm}$ laser ( $\sim 10 \mathrm{~mW})$ which is focused onto the sample plane using a $60 \mathrm{X}$ water immersion Nikon objective (backscattered configuration). The laser spot size was set to $0.8 \mu \mathrm{m}$ allowing for localized Raman measurements. Raman spectrum were recorded on a deep depletion charge coupled device (CCD) detector (Renishaw RenCam). The recorded Raman spectrum was digitalized and displayed on a PC using Renishaw WiRE software. The spectra were background subtracted with a customwritten Matlab code (see methods in (86)). First, an exploration of the spectral data set was performed using Principal Component Analysis (PCA). Second Multivariate Curve Resolution (MCR) algorithm were performed to extract molecular components from the Raman spectral dataset (spectral profile and abundance in each measured sample). For PCA and MCR analysis, the PLS toolbox in Matlab was used.

Calcium imaging (related to Suppl. Fig. 3D) Progenitor cells were added to a Concanavalin Acoated glass bottom dish $\left(0.05 \mathrm{mg} / \mathrm{mL}\right.$ by incubation at $31^{\circ} \mathrm{C}$ for $\left.1.5 \mathrm{~h}\right)$ and loaded for $20 \mathrm{~min}$ at $28^{\circ} \mathrm{C}$ with $5 \mu \mathrm{M}$ of FURA-2 plus a nonionic surfactant $(0.02 \%$ pluronic $\mathrm{F}-127)$ dissolved in DMSO. The cells were then washed before initiating the experiment. The fluorescence signal was measured in a standard bath solution containing $140 \mathrm{mM} \mathrm{NaCl}, 2.5 \mathrm{mM} \mathrm{KCl}, 1.2 \mathrm{mM} \mathrm{CaCl}, 0.5$ $\mathrm{mM} \mathrm{MgCl} 2,10 \mathrm{mM} \mathrm{HEPES}$, and $5 \mathrm{mM}$ glucose, $\mathrm{pH} 7.4$, adjusted with $\mathrm{NaOH}(\sim 320-$ $340 \mathrm{mOsm} / \mathrm{l})$ ). The following concentrations of reagents were used: $20 \mu \mathrm{M}$ of YODA1 (to activate Piezo1, Tocris Bioscience), $10 \mu \mathrm{M}$ GsMTx4 (Tocris). Fluorescence time lapse measurements of intracellular calcium concentrations were obtained using an Olympus IX70 inverted microscope (Hamburg, Germany) with a 40x oil-immersion objective (Olympus). A Polychrome IV monochromator (Till Photonics, Martinsried, Germany) supplied the excitation light (340 and 380 $\mathrm{nm}$ ), which was directed towards the cells in the field of view by a 505DR dichromatic mirror (Omega Optical, Brattleboro, VT). Fluorescence images were collected by a digital chargecoupled device camera (Hamamatsu Photonics, Hamamatsu City, Japan), after their passage through a 535DF emission filter (Omega Optical), using the AquaCosmos software program (Hamamatsu Photonics). Cytosolic calcium concentration was presented as the ratio of emitted fluorescence after excitation at 340 and $380 \mathrm{~nm}$ relative to baseline.

\section{Data Analysis}

Myosin II/actin accumulation and relative enrichment at the cortex Myosin and actin relative cortical accumulation values were quantified from confocal images of non-polarized progenitor cells acquired as described before, using a custom-written script in Matlab (2017b, Mathworks). Quantification was performed in non-polarized cells given that polarized cells present an inhomogeneous cell cortex with an increase in cortical density from the cell front towards the rear. The relative cortical accumulation is defined as: $\left(I_{\text {cortex }}-I_{\text {bleb }}\right) / I_{\text {bleb }}$. Cortical intensities were quantified by manually selecting the cortical region where the fluorescence signals are homogenous. The statistics over many cells was used to calculate the median of the mean peak intensities of the cortical regions. The bleb intensity in a single cell is calculated by computing the mean intensity in a manually selected rectangular region in the bleb. Relative myosin II accumulation in vivo was quantified on raw data using Fiji (plot profile tool, Fiji) and for each ratio (peak to averaged cytosolic intensity fluorescence) the distance of the corresponding cell to the yolk margin was measured. Nuclear aspect ratio was calculated in Fiji (measurement tool, Fiji) and for each nucleus the normalized distance to the yolk margin was measured. 
Cell size, bleb size and nuclear size estimation Cell and nuclear diameter measurements were calculated with Fiji (Measure tool, Fiji) from myosin II-GFP confocal images of non-polarized progenitor cells; transmission images were used as control. Bleb sizes were quantified from bright fields movies by segmenting single non-polarized cells and manually selecting the bleb and cell regions using Fiji (Measure tool, Fiji).

Myosin accumulation during mitosis (related to figure 2L) Myosin II-GFP time lapse movies of cells undergoing spontaneous mitosis under $7 \mu \mathrm{m}$ confinement were analyzed. For each movie the time point $\mathrm{t}=0$ was defined as the first frame in which the myosin II-GFP signal diffused into the nuclear region (from which it is excluded in interphase cells), indicative of nuclear envelope breakdown. The movies were temporally aligned according to this time frame and successive time points defined according to it. Therefore $\mathrm{t}=-1 \mathrm{~min}$ refers to cells in interphase and $\mathrm{t}>0$ to cells undergoing mitosis.

Lap2B-eGFP nuclear analysis Inner nuclear membrane properties were analyzed using confocal images of unpolarized progenitor cells expressing LapB2-eGFP images in Python using the ScikitImage library (https://scikit-image.org/). We first determined the inner and outer outlines using the contour detection function and used a median filter for smoothing. From that we determined area, perimeter and the convex image. The ratio in between the inner area $\left(A_{\text {in }}\right)$ and the associated convex area $\left(C_{i n}\right)$ is defined as the invagination ratio, computed as $=1-\left(A_{\text {in }} / C_{i n}\right)$.

Lap2B-eGFP curvature analysis Nuclear envelop fluctuations and bending analysis was performed on Lap2B-eGFP cross-sectional confocal images of unpolarized progenitor cells. The nuclear envelop was manually tracked in Fiji and the discrete $\mathrm{x}-\mathrm{y}$ positions were further postprocessed using a custom made Matlab script. Between each pair of discrete $x-y$ positions a cardinal spline function was interpolated (tension=0) passing through all $\mathrm{x}-\mathrm{y}$ positions. The resulting spline vector was overlaid to the fluorescence image to manually control the match with the nuclear envelope circumference. The spline was further used to calculate the curvature along the line using 2D bending vectors. The histogram of bending vectors was compared between confined cells $(7 \mu \mathrm{m})$ and cells in suspension.

Calcium imaging Progenitor cells derived from WT embryos were stained with Calbryte520 AM, a calcium activity reporter. The cell perimeter was segmented using either myosin II-mCherry, LynTomato or a transmission image and the nucleoplasm manually selected using these same channels. The mean intensity in the Calbryte channel has been measured in Fiji.

Percentage of polarized cells Percentages of polarized cells were computed from bright field movies as the number of polarized cells/total cells. Stable-bleb polarized cells can be easily distinguished from non-polarized cells due to their different morphology (pear shaped versus rounded blebbing) and thanks to their different morphodynamics behavior (motile versus nonmotile).

FRET RhoA-Fret images of non-polarized progenitor stem cells have been analyzed with the FRET analyzer plugin in Fiji. Donor, acceptor and FRET images are used by the plugin to compute the FRET index and to obtain the FRET image.

Orai-YFP basal accumulation Orai-YFP intensity line profiles (basal membrane) were exported from Fiji and the intensity level changes were automatically detected in Matlab using the findchangepts function $(\mathrm{N}=2)$. For cells cultured in $7 \mu \mathrm{m}$ confinement a region with a mean intensity increase in the central region of the intensity profile was automatically detected; for cells cultured at $13 \mu \mathrm{m}$ confinement no change in the intensity could be detected.

cPLA 2 translocation ratio (related to Fig $\mathrm{S}_{3} \mathrm{~J}$ ) cPLA $_{2}$ translocation ratio was quantified only in progenitor stem cells that showed visible translocation via differential intensity of cPLA 2 -GFP in 
between the INM and the nucleoplasm (indicated in the plot by the percentage of translocation). In these cells, the cPLA - INM translocation ratio was defined as the ratio in between the fluorescence intensity at the INM divided by the intensity in the nucleoplasm.

Statistical tests Statistical significance tests were performed with either (1) the two-sample ttest using the ttest2 function in Matlab when the data followed a normal distribution or (2) a non-parametric Kruskal-Wallis test (Matlab) when the data were not normally distributed. In the case of multiple t-tests we corrected for multiple comparisons using the family wise error rate (FWER). Single pairwise datasets were considered non-significant (n.s.) if $p>0.01$. The following significance symbols have been used for the corresponding p-values: ${ }^{*} \mathrm{p}<0.01$, $* * \mathrm{p}<0.001$ and $* * * \mathrm{p}<0.0001$, while in multiple comparisons we adapted the $\mathrm{p}$-values using the FWER correction for each range of significance. All p-value indicators and sample sizes (N) were provided in figure legends. Data were obtained from at least three independent experiments. Unless indicated otherwise, points and bars represent mean and standard error of the mean. For the boxplots, the central horizontal line represents the median and the box the interquartile range (with the lower limit the first quartile or $25^{\text {th }}$ percentile and the upper limit the third quartile or $75^{\text {th }}$ percentile). 


\section{Supplementary Figures S1-S7}
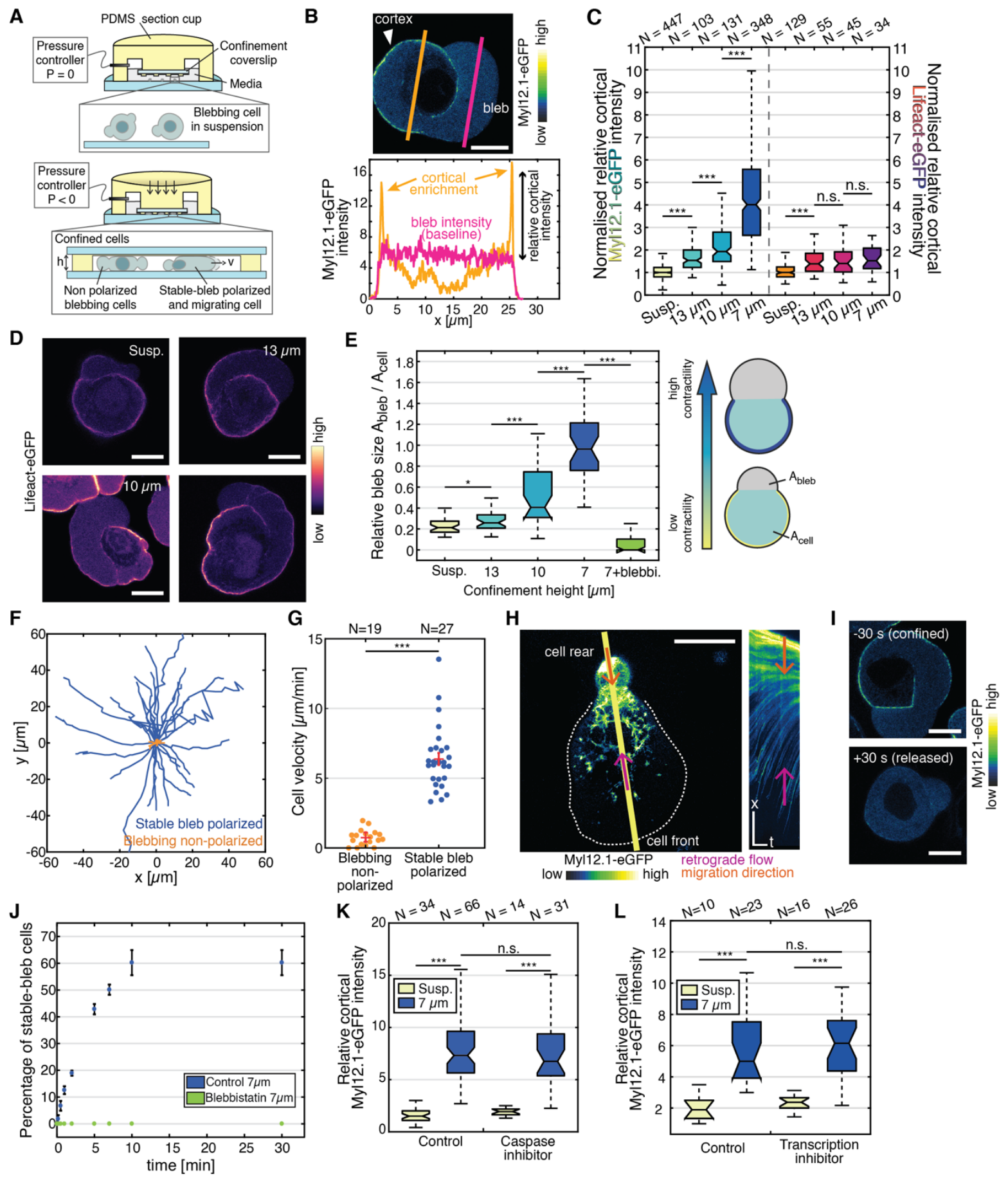

Figure S1. (A) Sketch of plan-parallel cell microconfinement using coverslips with PDMS micropillars of desired heights, with plate distance regulated by a pressure controller. (B) Top: representative confocal image of a single progenitor cell expressing myosin II-eGFP under $10 \mu \mathrm{m}$ confinement. White arrow points at cellular cortex. Bottom: myosin II-eGFP intensity plot along orange and magenta lines showing cortical enrichment and the intensity in the bleb protrusion, 
respectively (baseline). The relative cortical intensity was defined as the difference in between the cortical peak intensity and the bleb baseline intensity (as indicated by the black arrow) and was then normalized to the bleb intensity. Scale bar $10 \mu \mathrm{m}$. (C) Relative cortical myosin II-eGFP and LifeAct-GFP intensity normalized to the relative cortical suspension value for increasing confinement in un-polarized progenitor stem cells. (D) Exemplary confocal images of progenitor cells expressing Lifeact-GFP under different confinement heights. Scale bars $10 \mu \mathrm{m}$. (E) Normalized bleb to cell area for cells cultured in control conditions (Suspension, Susp.), different confinement heights and for $7 \mu \mathrm{m}$ confinement supplemented with $10 \mu \mathrm{M}$ Blebbistatin. For all conditions $\mathrm{N}=35$. (F, G) Cell tracks $(\mathrm{F})$, and mean cell velocity $(\mathrm{G})$ for stable-bleb polarized (blue) and blebbing non-polarized (orange) progenitor stem cells cultured in $7 \mu \mathrm{m}$ confinement. Red lines represent mean and standard error of the mean. (H) Exemplary confocal image of the basal cortex of a stable-bleb cell expressing myosin II-eGFP under $7 \mu \mathrm{m}$ confinement and associated kymograph along yellow line. Scale bars: left $20 \mu \mathrm{m}$, kymograph $10 \mu \mathrm{m}(\mathrm{x})$ and $10 \mathrm{~s}(\mathrm{t})$. Magenta arrow indicates the direction of the cortical retrograde flow and orange arrow the direction of cell migration in both panels. (I) Representative fluorescence image of a progenitor stem cell at $7 \mu \mathrm{m}$ confinement before release of cell confinement $(-30 \mathrm{~s})$ and after confinement release $(+30 \mathrm{~s})$. Scale bars $10 \mu \mathrm{m}$. (J) Percentage of polarized migratory stable-bleb cells over time after applying $7 \mu \mathrm{m}$ confinement $(\mathrm{t}=0)$ for progenitor stem cells cultured in control conditions (DMEM, blue, $\mathrm{N}=620$ ) or with Blebbistatin (green, $\mathrm{N}=486$ ); $\mathrm{t}_{1 / 2} \sim 4 \mathrm{~min}$. (K) Relative cortical myosin II intensity for control cells or cells treated with caspase inhibitor in suspension and $7 \mu \mathrm{m}$ confinement. (L) Relative cortical myosin II intensity for control cells or cells treated with Actinomycin D (transcription inhibitor) in suspension and $7 \mu \mathrm{m}$ confinement. $* * * p<0.0001,{ }^{*} \mathrm{p}<0.001,{ }^{*} \mathrm{p}<0.01$, not significant (n.s.). 


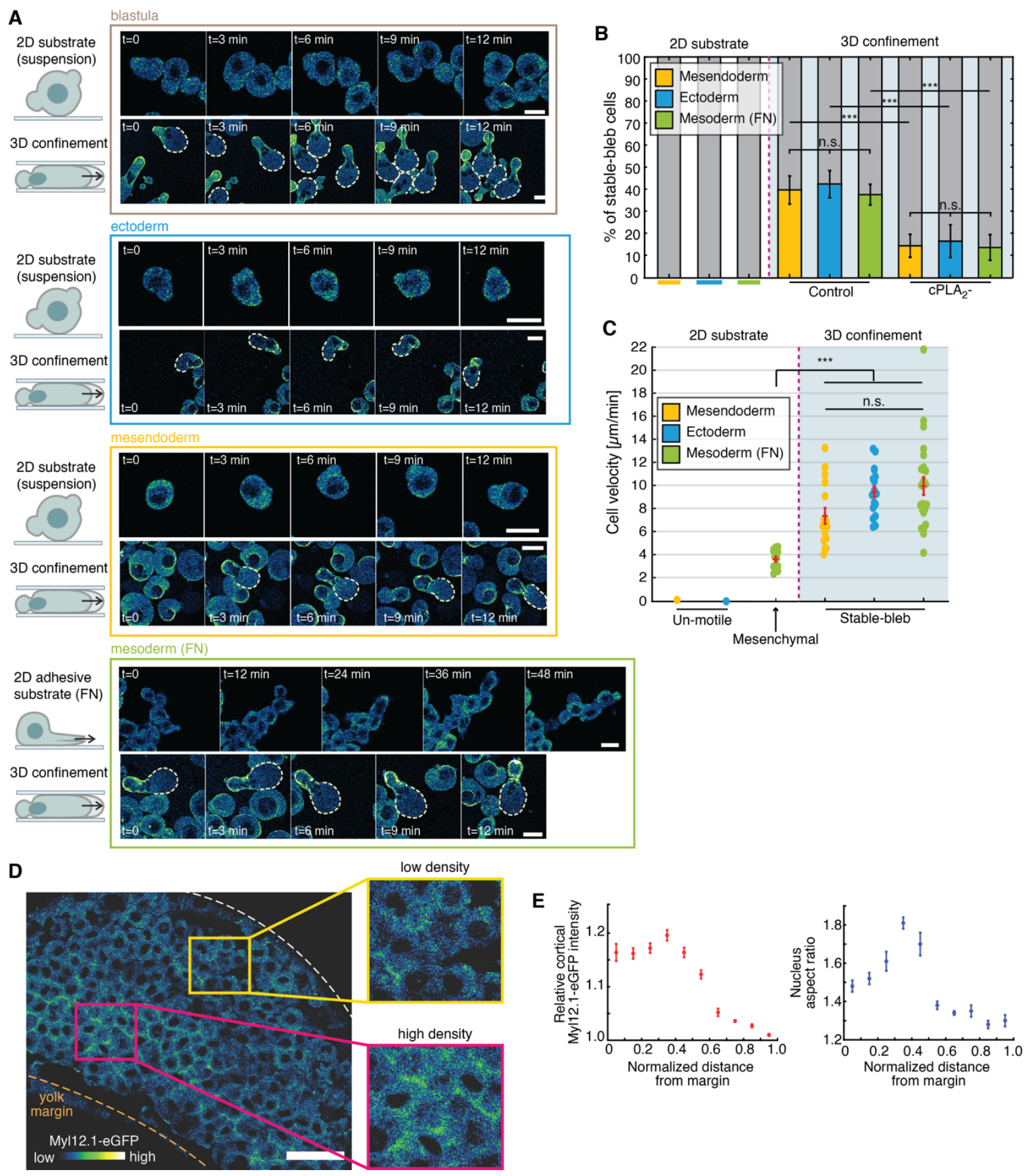

Figure S2. (A) Representative confocal time lapse images of (from top to bottom) blastula cells (4 hpf) and induced ectoderm, mesendoderm cultured on non-adhesive surfaces and mesoderm cells cultured on fibronectin in 2D versus 3D confinement. Blastula, mesendoderm and ectoderm are non-motile when plated on a non-adhesive 2D substrate and transform to stable-bleb cells if cultured in confinement $(7 \mu \mathrm{m})$. Mesoderm cells are motile when cultured on fibronectin (mesenchymal migration mode) but transform to stable-bleb cells when confined $(7 \mu \mathrm{m})$. Dashed lines delimitate the front of stable bleb cells. Scale bars $20 \mu \mathrm{m}$. (B) Percentage of stable-bleb cells for induced mesendoderm and ectoderm cells on passivated surfaces and mesoderm cells on fibronectin-coated surfaces for suspension (2D) and $7 \mu \mathrm{m}$ confinement (3D). $\mathrm{N}>350$ for all 
conditions. (C) Cell velocity for mesendoderm and ectoderm cells on passivated surfaces and mesoderm cells on fibronectin-coated surfaces in suspension (2D) and $7 \mu \mathrm{m}$ confinement (3D). Red lines represent mean and standard error of the mean (sem). N: mesoderm on fibronectin in 2D $\mathrm{N}=14$; mesendoderm 3D N=17; ectoderm 3D N=19; mesoderm on fibronectin 3D N=25. (D) Exemplary in vivo image of embryonic myosin II-eGFP distribution at the lateral margin at 4.5 hpf. The yolk interface (orange dashed line) and embryonic tissue surface (white dashed line) are highlighted. Scale bar $50 \mu \mathrm{m}$. (E) Relative cortical myosin II intensity and nuclear aspect ratio as a function of normalized distance from the yolk margin. $\mathrm{N}=58$ cells from 2 embryos. Data represent mean and standard error of the mean. ${ }^{* * *} \mathrm{p}<0.0001$, not significant (n.s.). 

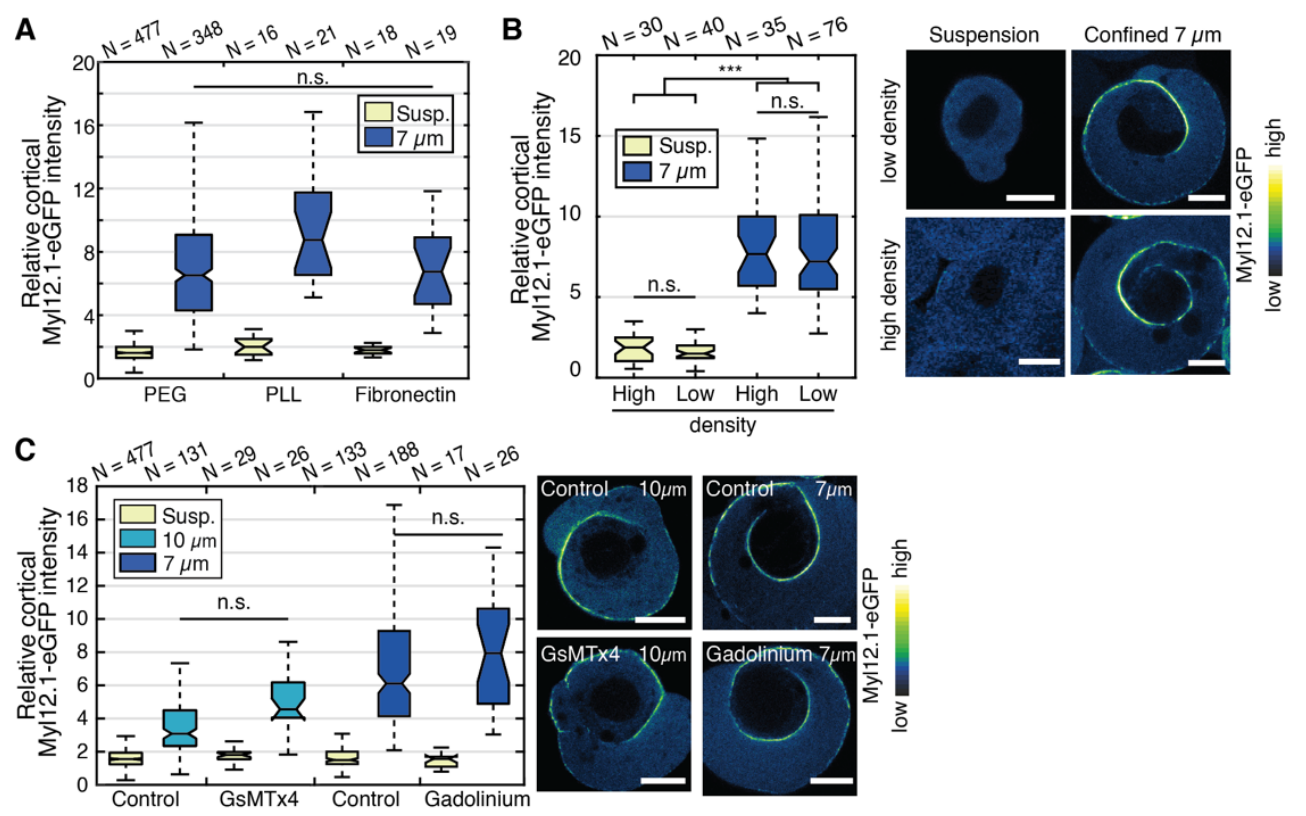

D
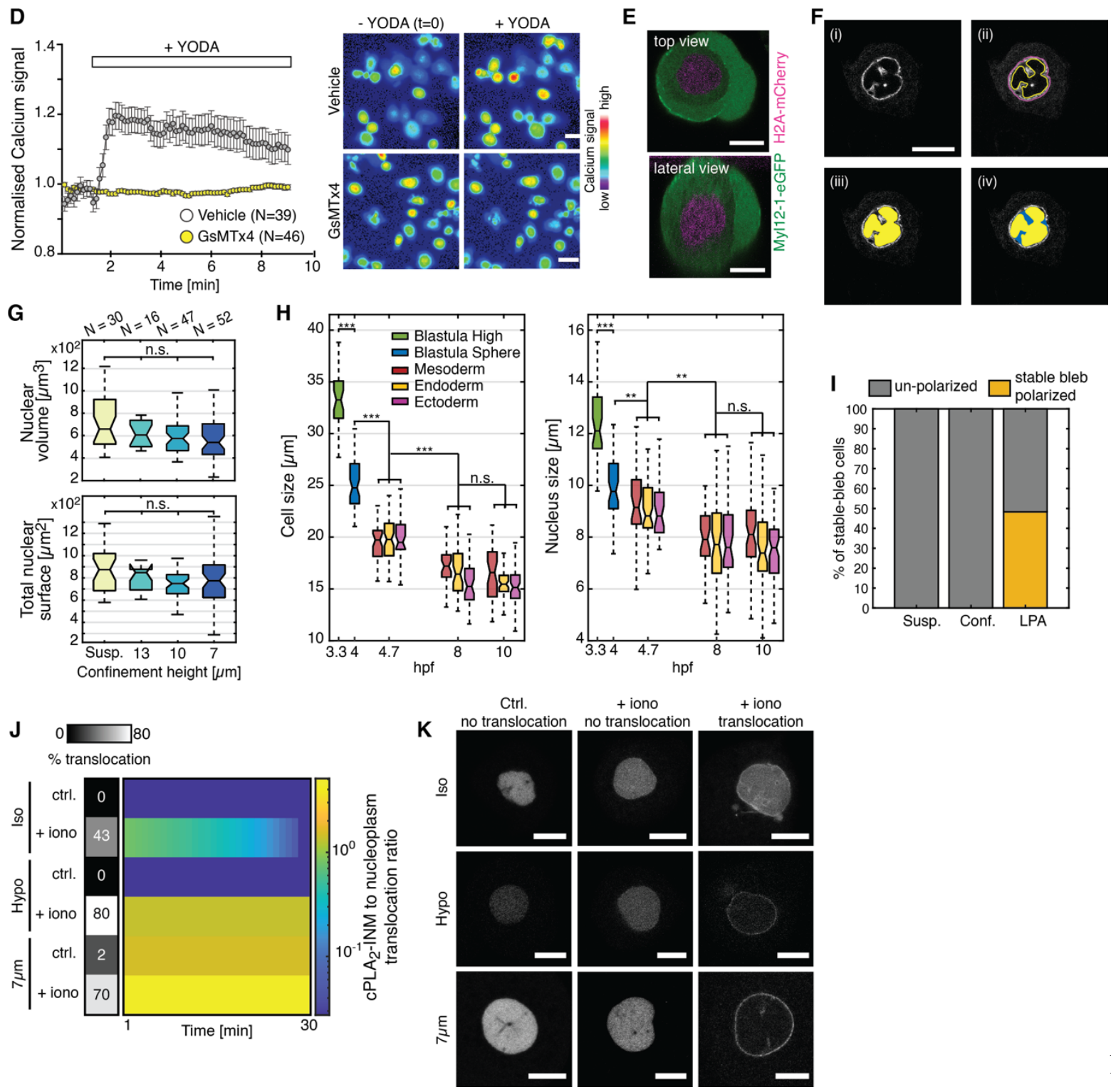
Figure S3. (A) Relative cortical myosin II enrichment under $7 \mu \mathrm{m}$ confinement for cells cultured on passivated (PLL-PEG) or adhesive surfaces (PLL, fibronectin). (B) Relative cortical myosin II intensity for cells cultured in DMEM (suspension) or under $7 \mu \mathrm{m}$ confinement for isolated cells (no cell-cell contact, low density) or contacting cells under high cell density and exemplary confocal images of progenitor cells expressing myosin II-eGFP under the indicated conditions (right). (C) Relative cortical myosin II intensity and representative confocal image for cells expressing myosin II-eGFP in control conditions or treated with the cationic mechanosensitive channel inhibitor GsMTx4 and with Gadolinium (inhibitor of stretch-activated ion channels) in suspension and indicated confinement heights. (D) Normalized calcium signal (left) and representative images (right) in isolated progenitor cells under stimulation with the Piezo1 activator YODA (gray, $\mathrm{N}=39$ ) and in the presence of YODA supplemented with GsMTx4 (yellow, $\mathrm{N}=46$ ). Data represent mean and standard error of the mean. (E) Representative top view (top) and lateral view (bottom) confocal images of cells expressing myosin II-eGFP and H2A-mCherry cultured in suspension (DMEM), (F) Exemplary Lap2B-eGFP image analysis protocol: (i) raw image; (ii) detection of inner and outer contour (magenta and yellow line); (iii) inner surface area (yellow); (iv) detection of convex area of (iii), (blue). The invagination ratio (IR) is defined as $1-$ the ratio in between the yellow and blue area. (G) Nuclear surface and volume for cells in suspension and variable confinement heights. (H) Cell size (left) and nuclear size (right) during embryo development between 3.3 hours post fertilization (hpf) and $10 \mathrm{hpf}$ for undifferentiated progenitor stem cells and induced mesoderm, ectoderm and endoderm progenitor cells $(4.7,8,10$ hpf). In order: $\mathrm{N}=63$ (blastula high); $\mathrm{N}=60$ (blastula sphere); $\mathrm{N}=39,71,38$ (mesoderm, endoderm, ectoderm - 4.7 hpf); N=41, 49, 43 (mesoderm, endoderm, ectoderm - 8 hpf); N=43, 65, 63 (mesoderm, endoderm, ectoderm - $10 \mathrm{hpf}$ ). (I) Percentage of stable-bleb polarized cells after treatment with $1 \mu \mathrm{M}$ nocodazole in suspension (unconfined, $\mathrm{N}>100$ ), $7 \mu \mathrm{m}$ confined $(\mathrm{N}>100)$ and in suspension with the addition of $50 \mu \mathrm{M}$ LPA $(\mathrm{N}=40)$. (J) cPLA 2 nucleoplasm to inner nuclear membrane (INM) translocation ratio for cells cultured in DMEM (isotonic), hypotonic condition or under $7 \mu \mathrm{m}$ confinement with or without the addition of ionomycin. The grey-scaled bar indicates the percentage of cells in which cPLA 2 -INM translocation is observed and the colormap shows the dynamics of the translocation ratio, defined as the ratio in between the fluorescence intensity of cPLA 2 -GFP at the inner nuclear membrane and in the nucleoplasm. (K) Representative confocal images of unpolarized progenitor cells expressing cPLA $_{2}$-GFP cultured in isotonic, hypotonic conditions or for $7 \mu \mathrm{m}$ confinement with or without the addition of ionomycin. Nuclei with or without $\mathrm{CPLA}_{2}$-INM translocation are shown in columns as indicated. All scale bars 10 $\mu \mathrm{m}$ except (D) $20 \mu \mathrm{m} .{ }^{* * *} \mathrm{p}<0.0001,{ }^{*} \mathrm{p}<0.001,{ }^{*} \mathrm{p}<0.01$, not significant (n.s.). 
A

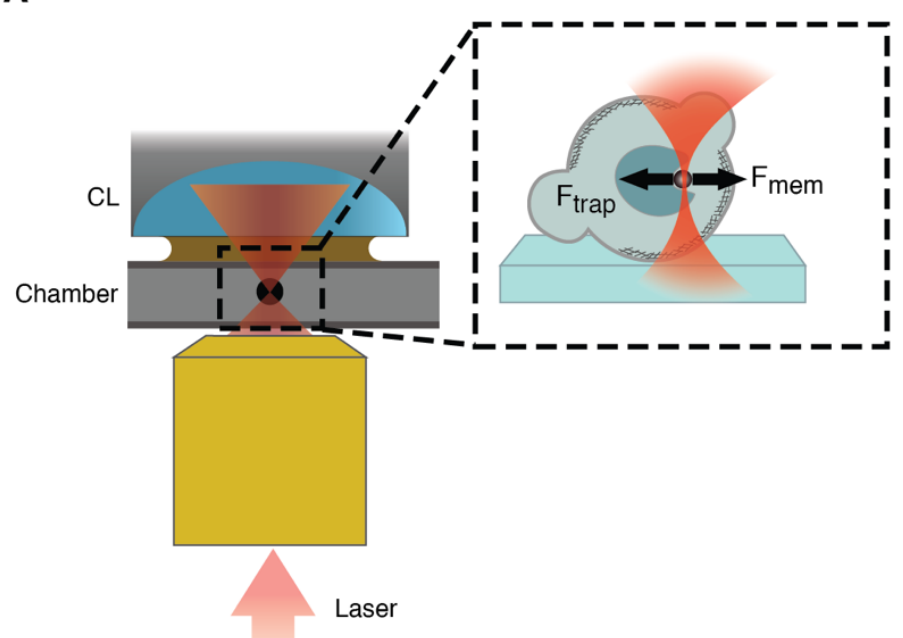

B

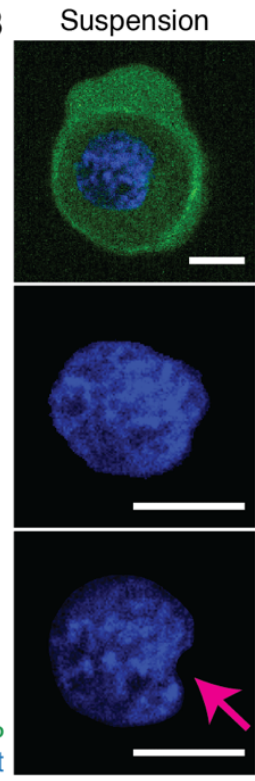

C Confined

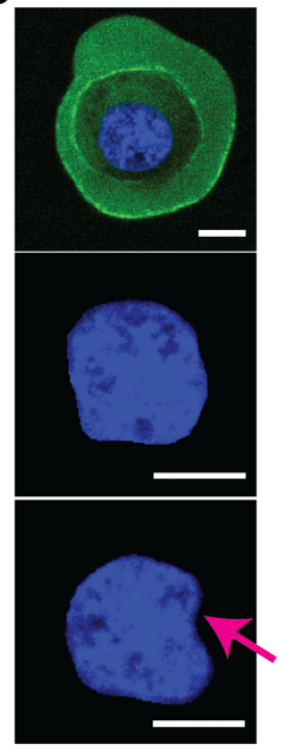

D

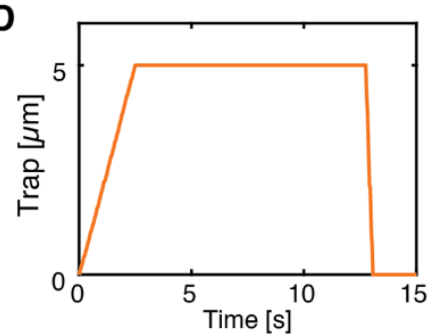

E

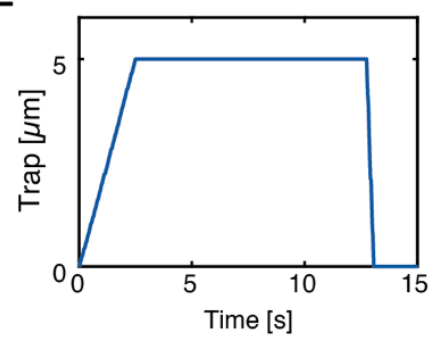

H

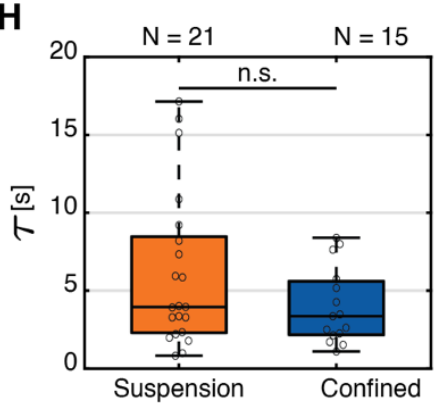

Myl12.1-eGFP

DNA-Hoechst
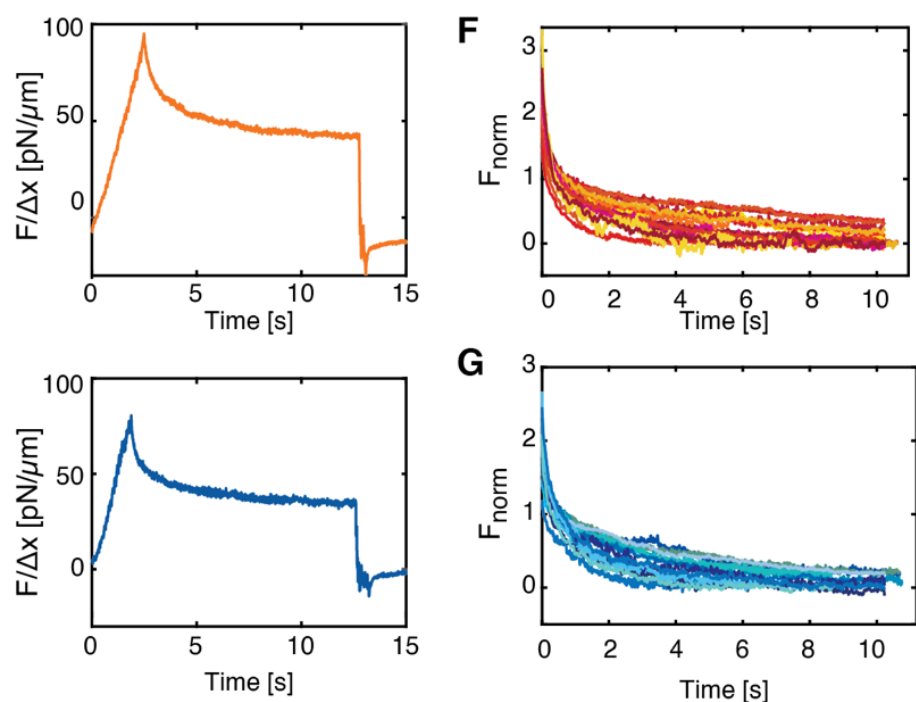

G

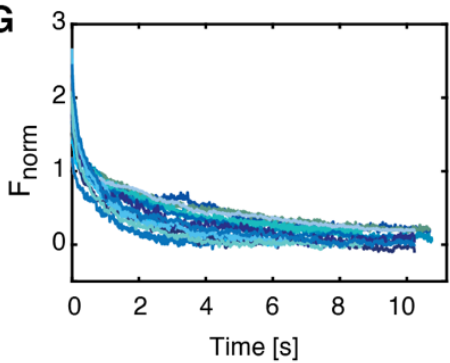

I

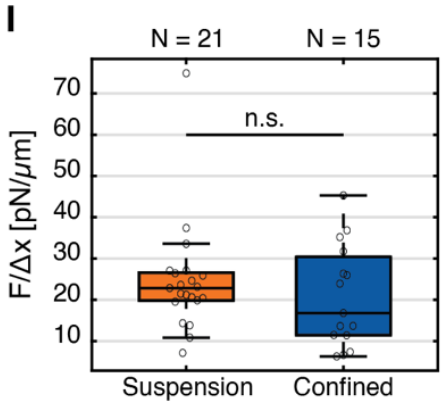

J
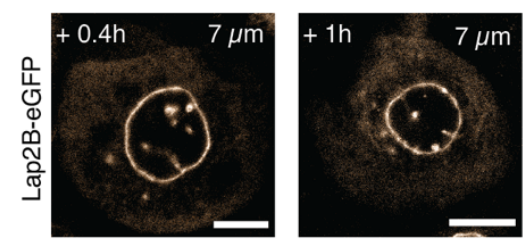

Figure S4. Mechanical characterization of cell nuclei in live cells with optical micro-manipulation and spinning-disk confocal microscopy. (A) Schematic showing the trapping beam focused through a microscope objective and captured by a condenser lens (CL) to carry out lightmomentum force measurements on an optical trap deforming the nuclear membrane. $F_{\text {mem }}$ and $F_{\text {trap }}$ are the nuclear membrane and trapping forces exerted onto the trapped $1 \mu \mathrm{m}$ latex bead, 
respectively. (B,C) Exemplary fluorescence image of a cell in suspension (B) or confinement $(\mathrm{C})$ expressing myosin II-eGFP and DNA-Hoechst (top) and snapshot prior to (middle) and during (bottom) indentation on the nucleus. The magenta arrow indicates the position of the trapped micro-bead. (D,E) Trap trajectory (left) and nuclear force profile (right, normalized to nuclear indentation) for exemplary force relaxation experiments in cells cultured in DMEM in suspension (D) or under $10 \mu \mathrm{m}$ confinement $(\mathrm{E})$. (F,G) Normalized and time-shifted nuclear force-relaxations tracks (as in panel $\mathrm{D}, \mathrm{E})$ for cells in suspension $(\mathrm{F}, \mathrm{N}=21)$ and under $10 \mu \mathrm{m}$ confinement $(\mathrm{G}$, $\mathrm{N}=15$ ). (H) Boxplot of characteristic relaxation time $(\tau)$ obtained from fitting an exponential decay function with plateau offset to the force-relaxation curves shown in (F,G). (I) Boxplot of static force component obtained from fitting an exponential decay to the force-relaxation curves. $(\mathbf{J})$ Exemplary confocal images of cells expressing Lap2B-eGFP (inner nuclear membrane marker) for different time points (time indicates hour after confinement) at $7 \mu \mathrm{m}$ confinement. Not significant (n.s.). 

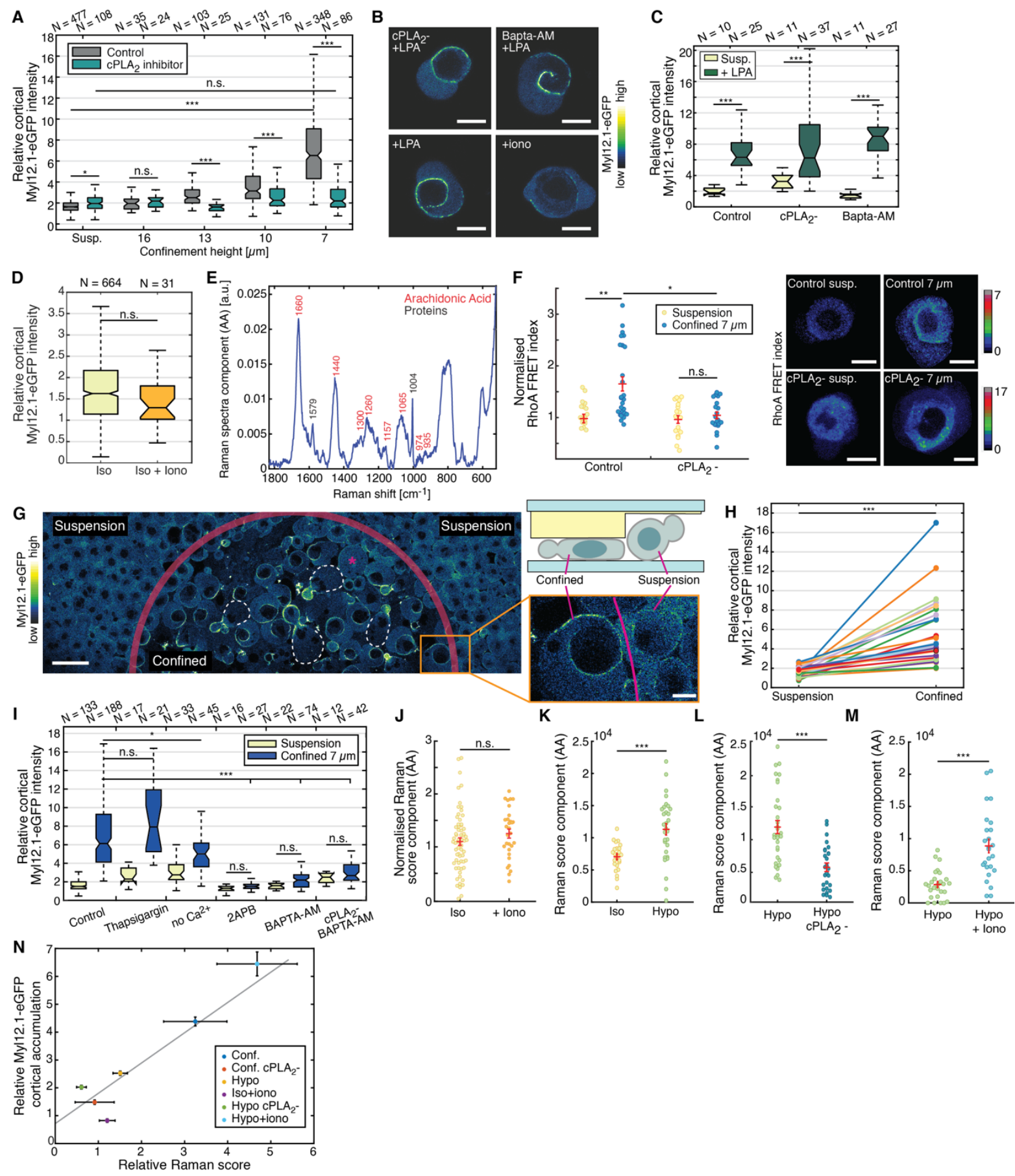

Figure S5. (A) Relative cortical myosin II enrichment for cells cultured in suspension (DMEM) or supplemented with $\mathrm{cPLA}_{2}$ inhibitor for decreasing confinement heights. (B) Exemplary confocal images of progenitor cells expressing myosin II-eGFP cultured in suspension with cPLA 2 inhibitor $+50 \mu \mathrm{M}$ LPA, Bapta-AM $+50 \mu \mathrm{M}$ LPA, $50 \mu \mathrm{M}$ LPA alone or ionomyocin (iono). Scale bars $10 \mu \mathrm{m}$. (C) Relative cortical myosin II intensity for cells cultured in suspension (DMEM) and upon $50 \mu \mathrm{M}$ LPA addition in control conditions and for cells treated with cPLA 2 inhibitor or BaptaAM. (D) Relative cortical myosin II enrichment for cells cultured in suspension (DMEM) or supplemented with ionomycin. (E) Components of the Raman spectra associated with arachidonic 
acid (AA) used for the quantification of AA production (related to Fig. 2). Raman peaks indicated in red are specific for AA. (F) Scatter plot of Fret index for unconfined (suspension) and confined cells cultured in control (DMEM) conditions or supplemented with cPLA $\mathrm{A}_{2}$ inhibitor. Red lines represent mean and (sem). From left to right: $\mathrm{N}=20, \mathrm{~N}=26, \mathrm{~N}=19, \mathrm{~N}=21$. Right: Representative images showing the Fret index of cells in suspension (Susp., unconfined) and $7 \mu \mathrm{m}$ confinement in control conditions or supplemented with cPLA ${ }_{2}$ inhibitor. Scale bars $10 \mu \mathrm{m}$. (G) Representative stitched confocal view of cells expressing myosin II-eGFP cultured in DMEM and confined below a micropillar (approx. height $7 \mu \mathrm{m}$ ) resulting in confined cells and non-confined cells outside the micropillar in close proximity. The magenta line shows the edge of the pillar; the dashed lines indicate the front of stable-bleb polarized/migrating cells and the magenta asterisk a mitotic cell. Scale bar $50 \mu \mathrm{m}$. The zoomed view and sketch show adjacent confined and unconfined cells. Scale bar $20 \mu \mathrm{m}$. (H) Relative cortical myosin II intensity for confined/non-confined pairs of cells in contact at the micropillar edge, as shown in panel $\mathrm{G}$ of this figure. $\mathrm{N}=27$ pairs. Myosin accumulation levels in non-confined cells of this experiment show no significant difference from control cells cultured in suspension. (I) Relative cortical myosin II intensity for cells cultured in control (DMEM) or under different conditions, Thapsigargin (Thapsi.), Calcium free media (no $\mathrm{Ca}^{2+}$ ), 2APB, Bapta-AM and Bapta-AM+cPLA 2 inhibitor. (J-M) Scores of Raman component associated with intracellular AA levels in control DMEM suspension (Iso, $\mathrm{N}=26$ ) and in the presence of $1 \mu \mathrm{M}$ ionomycin (Iono, $\mathrm{N}=30$ ), $(\mathrm{K})$ in control DMEM suspension (Iso, $\mathrm{N}=24$ ) and in hypotonic condition (Hypo, $\mathrm{N}=32$ ), ( $\mathrm{L}$ ) in hypotonic condition (Hypo, $\mathrm{N}=32$ ) and with the presence of $\mathrm{cPLA}_{2}$ inhibitor (Hypo $+\mathrm{cPLA}_{2-}, \mathrm{N}=31$ ), and $(\mathrm{M})$ in hypotonic condition (Hypo, $\mathrm{N}=27$ ) and in hypotonic condition supplemented with ionomycin (Hypo + Iono, $\mathrm{N}=25$ ). Red lines represent mean and sem. (N) Myosin II cortical accumulation as a function of relative AA Raman score for all tested conditions. Both values are normalized to suspension (isotonic, control). The line indicates a linear regression, $\mathrm{R}^{2}=0.68$ (considering only three last point: $\mathrm{R}^{2}=0.99$ ). Data points indicate mean and bars standard error of the mean (sem). Scale bars $10 \mu \mathrm{m}$ except for panel G. ${ }^{* * *} \mathrm{p}<0.0001,{ }^{* *} \mathrm{p}<0.001,{ }^{*} \mathrm{p}<0.01$, not significant (n.s.). 

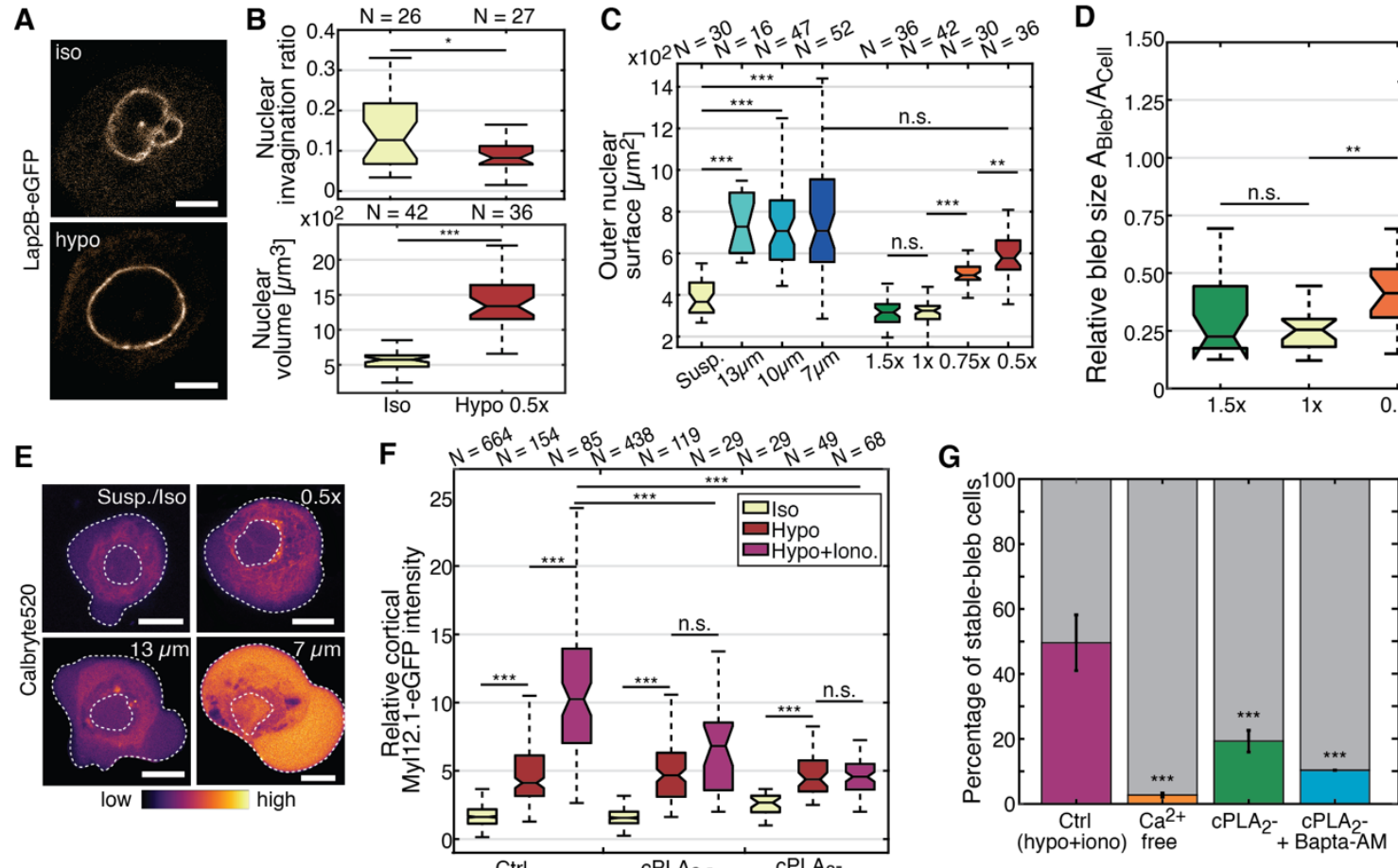

E

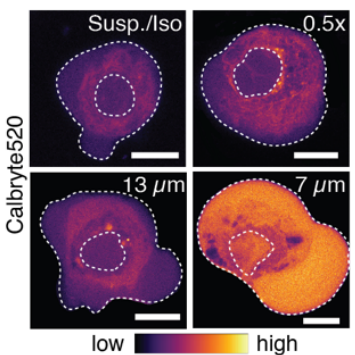

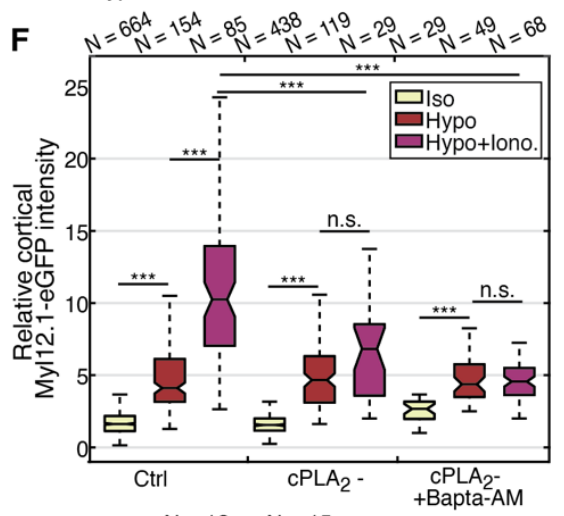

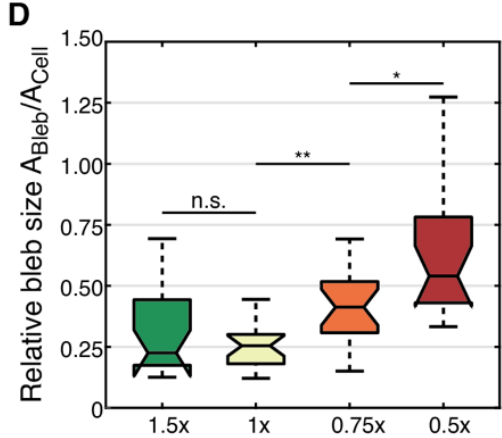

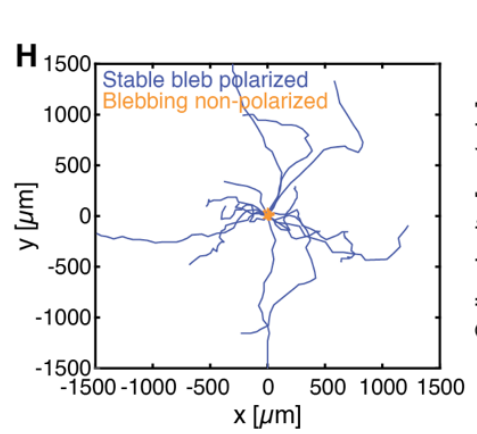
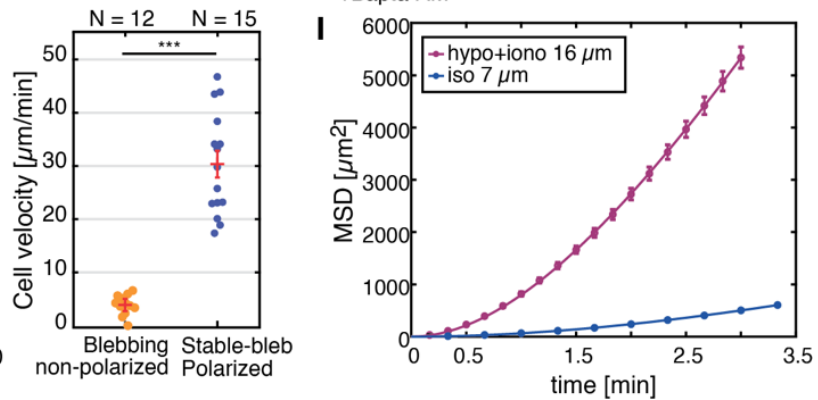

J
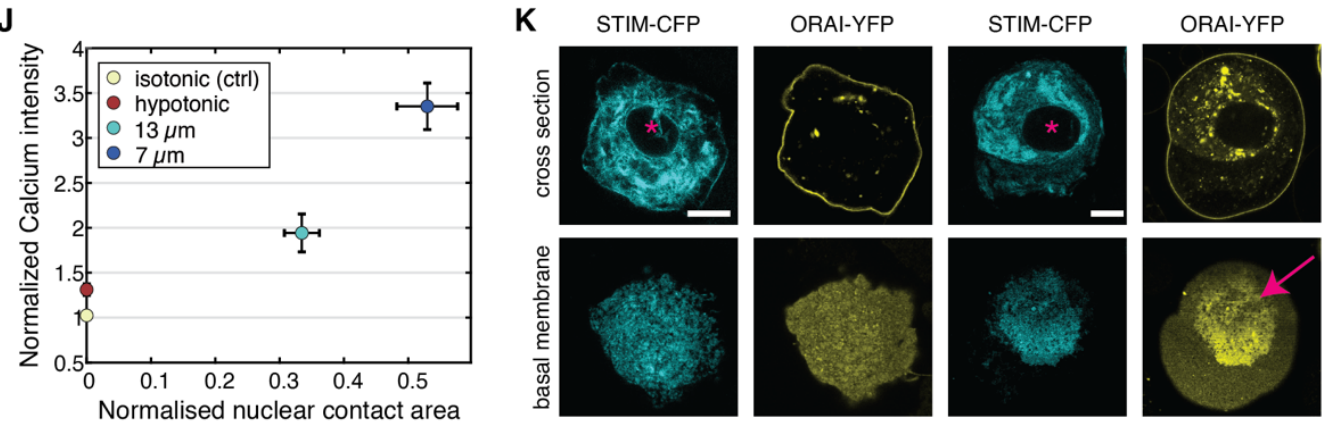

transversal view $7 \mu \mathrm{m}$ confinement
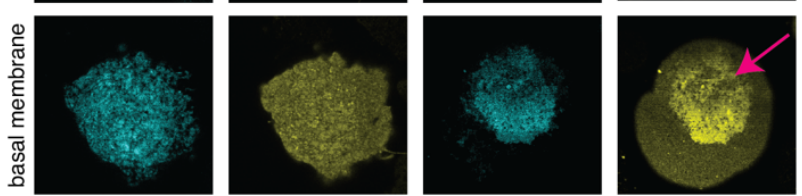

STIM-CFP

$13 \mu \mathrm{m}$ confinement

$7 \mu \mathrm{m}$ confinement
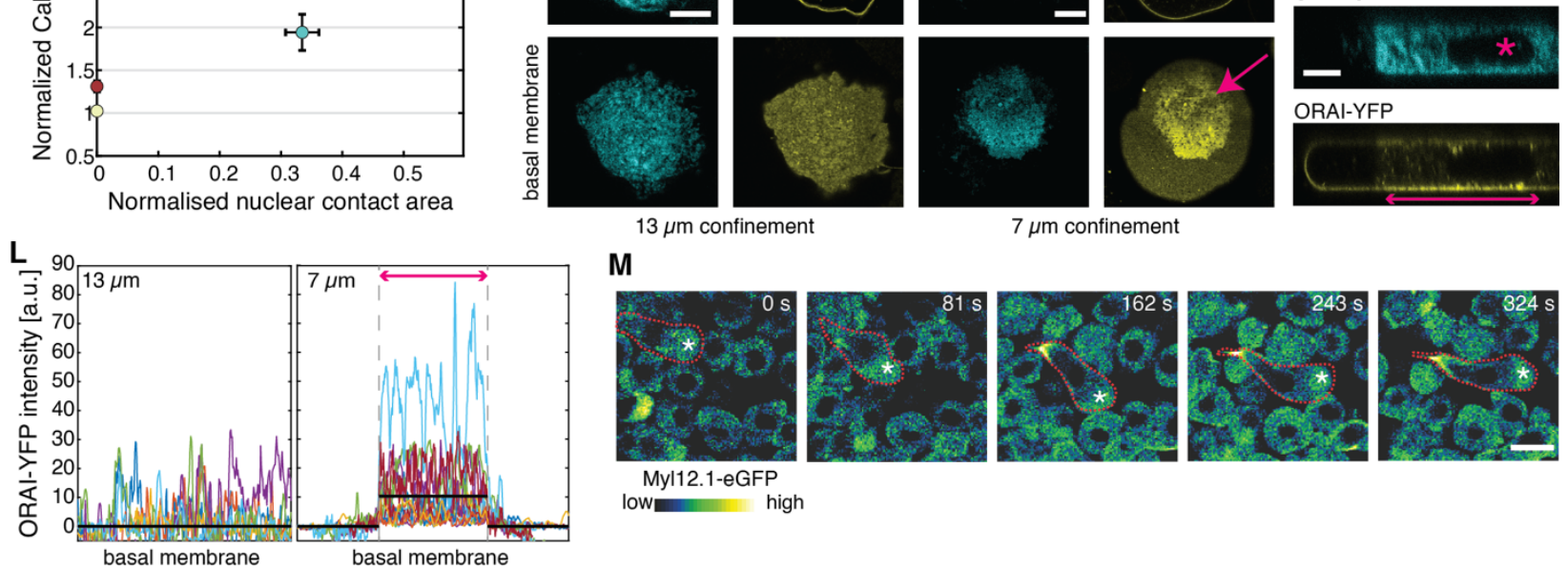

M
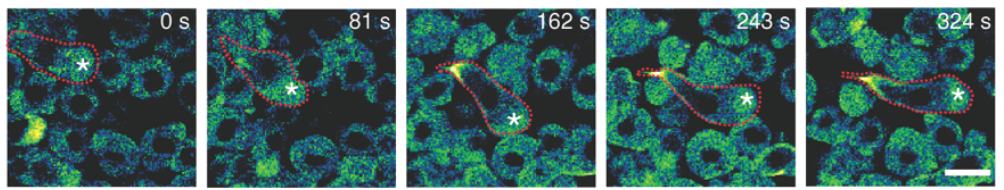

Myl12.1-eGFP

low high 
Figure S6. (A) Exemplary confocal images of progenitor stem cells expressing Lap2B-eGFP cultured in isotonic (top) and hypotonic (bottom) conditions. Scale bars $5 \mu \mathrm{m}$. (B) Boxplot of nuclear invagination ratio (top), nuclear volume (bottom) for cells cultured in isotonic and hypotonic media. (C) Outer nuclear surface for cells cultured at decreasing confinement height or at different osmolarities. (D) Relative bleb to cell size under different osmolarity conditions. $\mathrm{N}=25$ for each condition. (E) Representative confocal images of cells stained with Calbryte520 AM in isotonic condition (suspension), under $0.5 x$ hypotonic shock or confinement at $13 / 7 \mu \mathrm{m}$ height. Dashed lines outline the cell and nucleus perimeter. (F) Relative cortical myosin II intensity for progenitor cells cultured in isotonic, hypotonic and hypotonic + ionomycin conditions supplemented with $\mathrm{cPLA}_{2}$ inhibitor alone or in combination with Bapta-AM. (G) Percentage of polarized stable-bleb cells under reference hypotonic conditions with $1 \mu \mathrm{M}$ ionomycin (magenta), depletion of extracellular calcium (orange), $\mathrm{CPLA}_{2}$ inhibition (green) and $\mathrm{CPLA}_{2}+$ Bapta-AM (blue). Statistical tests with respect to control. $\mathrm{N}>300$ for all conditions. (H) Left: Cell tracks for stable-bleb polarized (blue, motile) and blebbing non-polarized (orange, non-motile) progenitor stem cells cultured in hypotonic media supplemented with $1 \mu \mathrm{M}$ ionomycin under $16 \mu \mathrm{m}$ confinement (related to Fig. 4F). Right: Instantaneous cell speed of blebbing non-polarized cells versus polarized stable-bleb cells migrating in $16 \mu \mathrm{m}$ confinement for cells cultured in hypotonic media with ionomycin. Red lines represent mean and standard error of the mean (sem). (I) Mean square displacement (MSD) analysis of cell tracks related to (H). A persistent random walk model is fit to the data (Fürth formula) for $7 \mu \mathrm{m}$ confined cells (blue points, velocity and tracks shown in Fig. S1F,G) and hypo+ionomycin treated cells under $16 \mu \mathrm{m}$ confinement (magenta points, velocity shown in Fig. 4F), with persistence time of $\mathrm{P}_{\mathrm{t}}=1.9 \mathrm{~min}$ ( $2.8 \mathrm{~min}$ ), respectively. (J) Mean calcium intensity with respect to the normalized nuclear contact area for isotonic condition (control yellow, $\mathrm{N}=100$ ), hypotonic shock (red, $\mathrm{N}=39$ ), $13 \mu \mathrm{m}$ confinement (light blue, $\mathrm{N}=44$ ) and $7 \mu \mathrm{m}$ confinement (dark blue, $\mathrm{N}=33$ ). The nuclear contact area is normalized to the cross-sectional area for each cell. Points represent mean and bars the standard error of the mean. (K) Representative confocal images of cells expressing STIM-CFP and Orai-YFP at 13/7 $\mu \mathrm{m}$ confinement. Crosssections and basal membrane sections are shown along with the transversal view for $7 \mu \mathrm{m}$ confinement. Magenta asterisks indicate the nucleus and the arrow points at the region of the basal membrane for $7 \mu \mathrm{m}$ confinement where Orai-YFP accumulates (ER-PM contacts). (L) Orai-YFP intensity at the basal membrane for cells at $13 / 7 \mu \mathrm{m}$ confinement. Each line corresponds to one cell $(13 \mu \mathrm{m}: \mathrm{N}=6,7 \mu \mathrm{m}: \mathrm{N}=14)$. Black lines represent mean values. (M) Representative in vivo image of a motile stable-bleb cell (dashed red line) in a zebrafish embryo at blastula stage (4 hpf) injected with hypotonic media supplemented with ionomycin $(10 \mu \mathrm{M})$. Asterisk denotes cell front. Scale bar $10 \mu \mathrm{m}$ in all panels apart from panel transversal views of panel K and panel A $5 \mu \mathrm{m}$. ${ }^{* * *} \mathrm{p}<0.0001,{ }^{* *} \mathrm{p}<0.001,{ }^{*} \mathrm{p}<0.01$, not significant (n.s.). 

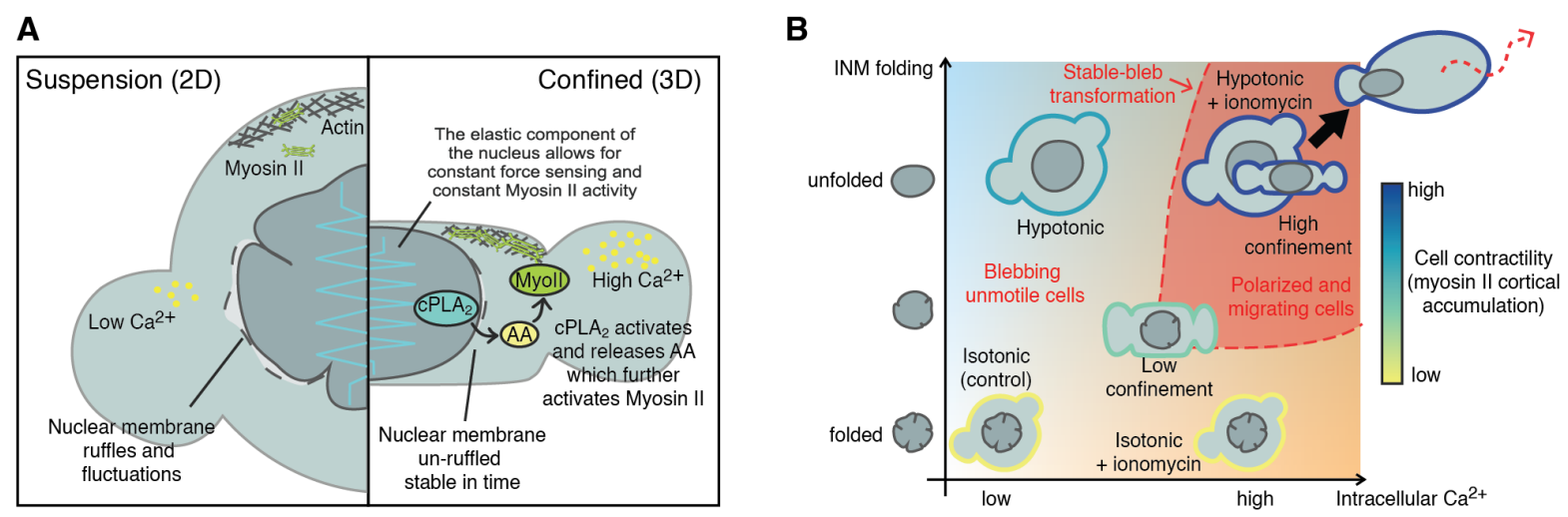

Figure S7. (A) Illustration of the mechano-transduction pathway that translates nucleus deformation into myosin II activation and re-localization to the cortex resulting in an increase in cortical contractility and regulating morphodynamic migration plasticity. (B) Schematic representation of inner nuclear membrane (INM) unfolding (top to bottom) and intracellular calcium levels (left to right) depending on the type of physical cell deformation (anisotropic cell compression and hypotonic swelling leading to isotropic cell stretching) and ectopic calcium regulation via ionomycin. 


\begin{tabular}{|c|c|c|c|c|}
\hline $\begin{array}{c}\text { Target molecule / } \\
\text { Process }\end{array}$ & Drug / Method used & $\begin{array}{c}\text { Effect on myosin II } \\
\text { activity }\end{array}$ & Data figure & Class / Kind \\
\hline Microtubules & Nocodazole & - & $4 C-E$ & \multirow{5}{*}{$\begin{array}{l}\text { Mechano- } \\
\text { sensors }\end{array}$} \\
\hline $\begin{array}{c}\text { Mechanosensitive ion } \\
\text { channels }\end{array}$ & $\begin{array}{c}\text { GMSTx4 } \\
\text { Gadolinium }\end{array}$ & - & $\mathrm{S} 3 \mathrm{C}$ & \\
\hline $\begin{array}{l}\text { Adhesions } \\
\text { (substrate) }\end{array}$ & $\begin{array}{l}\text { Different substrate } \\
\text { coatings }\end{array}$ & - & S2B, S3A & \\
\hline $\begin{array}{l}\text { Adhesions } \\
\text { (cell to cell) }\end{array}$ & $\begin{array}{l}\text { Single cells versus } \\
\text { high cell density }\end{array}$ & - & S3B & \\
\hline $\mathrm{CPLA}_{2}$ & Pyrrophenone & + & $\begin{array}{c}5 A-C, 6 C, 6 E, \\
\text { S2B } \\
\text { S5A-C, S5F, } \\
\text { S5L } \\
\text { S6F-G }\end{array}$ & \\
\hline Intracellular calcium & BAPTA-AM & + & S5I, S6F-G & \multirow{3}{*}{$\begin{array}{l}\text { Calcium } \\
\text { regulators }\end{array}$} \\
\hline $\begin{array}{l}\text { STIM/Orai complex } \\
\text { and IP3 receptor }\end{array}$ & 2-APB & + & S5I & \\
\hline SERCA pump & Thapsigargin & - & S5I & \\
\hline Myosin II & Blebbistatin (+) & + & $1 \mathrm{E}$ & \multirow{4}{*}{$\begin{array}{l}\text { Myosin II } \\
\text { regulators }\end{array}$} \\
\hline RhoA & dnRhoA & + & $6 \mathrm{~F}$ & \\
\hline ROCK & Y-27632 & + & $6 \mathrm{~F}$ & \\
\hline MLCK & ML-7 & - & $6 \mathrm{~F}$ & \\
\hline Transcription & Actinomycin D & - & S1L & \multirow{4}{*}{ Others } \\
\hline Apoptosis & Z-VAD(OMe)-FMK & - & S1K & \\
\hline Kinases & Staurosponin & + & $6 \mathrm{~F}$ & \\
\hline Paracrine signalling & Pillar experiment & - & S5G & \\
\hline
\end{tabular}

Supplementary Table S1. Table summarizing different inhibitors and methods used in order to identify and characterize the mechanotransduction pathway responsible for mechanosensitive cortical actomyosin regulation under cell shape deformation. 


\section{Captions for Movies S1 to S9}

Movie S1. Adaptive myosin II dynamics upon cell confinement and role of cPLA 2 in cell mechanotransduction (related to Fig. 1 and Fig. 3). Time lapse confocal fluorescence movies of progenitor cells expressing Myl12.1-eGFP (myosin II) on non-adhesive substrates (PLL-PEG) cultured in DMEM media in suspension (left), under $7 \mu \mathrm{m}$ confinement in control condition (middle) or supplemented with $1 \mu \mathrm{M}$ cPLA 2 inhibitor. Upon confinement, myosin II accumulates at the cortex in control condition and the accumulation is blocked by the inhibition of cPLA2.

Movie S2. Cortex remodeling during amoeboid stable-bleb cell transformation and cortical retrograde flow in stable-bleb polarized cells (related to Fig. 1 and Suppl. Fig. 1). (I) Time lapse confocal fluorescence movie of Myl12.1-eGFP (myosin II) localization during stable-bleb transformation of a progenitor cells under $7 \mu \mathrm{m}$ mechanical confinement: a non-polarized and nonmotile blebbing cell spontaneously polarizes into stable-bleb cell upon mechanical confinement and initiates cell migration. (II) Time lapse confocal fluorescence movie of the basal cortex of a stable-bleb polarized cell expressing Myl12.1-eGFP (myosin II) under $7 \mu \mathrm{m}$ mechanical confinement. Myosin II shows a cortical density gradient and retrograde flow (magenta arrow, opposite to the direction of migration indicated by the orange arrow).

Movie S3. Adaptive myosin II morphodynamics under confinement (related to Fig. 1-2 and Suppl. Fig 2). Confocal fluorescence time lapse movie of pluripotent progenitor cells (I, sphere stage) on non-adhesive substrate (PLL-PEG); ectoderm cells (II) on non-adhesive substrate (PLLPEG); and mesoderm cells on fibronectin (III) for 2D substrate (left) and 3D mechanical confinement ( $7 \mu \mathrm{m}$, right). Pluripotent and ectoderm cells are non-motile when plated on 2D substrate and transform into a stable-bleb polarized and motile phenotype upon confinement. Mesoderm cells plated on a 2D fibronectin substrate migrate with a mesenchymal phenotype and transform to stable-bleb amoeboid migration upon mechanical confinement.

Movie S4. Myosin II accumulation is reversible (related to Fig. 1). Confocal fluorescence time lapse movie of progenitor cells expressing Myl12.1-eGFP (myosin II) during confinement (10 $\mu \mathrm{m})$ and subsequent release (i) and for confined cells squeezing out from underneath a micropillar ("escape reflex", ii). Myosin II is rapidly re-localized from the cortex to the cytoplasm upon confinement release.

Movie S5. Mesenchymal-to-amoeboid transition: mesoderm cells transform to stable-bleb cells upon mechanical confinement (related to Fig. 2). Time lapse confocal fluorescence movie of mesendoderm-induced progenitor cells expressing Myl12.1-eGFP (myosin II) plated on fibronectin substrate showing mesenchymal migration (white asterisk indicates migrating cell, 
white arrow points at cell protrusions). Upon confinement $(7 \mu \mathrm{m})$, cells rapidly accumulate myosin II at the cortex and transform to stable-bleb polarized cell (magenta asterisks point at cell front).

Movie S6. The inner nuclear membrane is unfolded under mechanical shape deformation in confinement and the unfolding is stable over time (related to Fig. 3). Time lapse confocal movies of progenitor cells stained with Lap2b-eGFP (i) in suspension, (ii) during confinement and (iii) under $7 \mu \mathrm{m}$ confinement. The time lapse in (iii) was acquired $1 \mathrm{~h}$ after mechanical confinement.

Movie S7. Adaptive Myosin II dynamics under hypotonic conditions or ionomycin treatment (related to Fig. 7). Confocal fluorescence time lapse movie of progenitor cells expressing Myl12.1eGFP (myosin II) on non-adhesive substrate (PLL-PEG) in isotonic media (control, DMEM), upon hypotonic shock (adding milliQ water, $0.5 \mathrm{x}$ shock) and upon the addition of $1 \mu \mathrm{M}$ ionomycin. Hypotonic treatment is followed by a myosin II accumulation at the cortex; further addition of ionomycin leads to a pronounced myosin II accumulation and triggers cell polarization.

Movie S8. Cell dynamics under hypotonic conditions and ionomycin treatment (related to Fig. 7). Bright field time lapse movie of progenitor cells cultured in isotonic condition (top-left), hypotonic media (top-right), hypotonic media supplemented with $1 \mu \mathrm{M}$ ionomycin in suspension (bottomleft) or under $16 \mu \mathrm{m}$ confinement (bottom-right). Hypotonic conditions supplemented with $1 \mu \mathrm{M}$ ionomycin lead to rapid cell polarization and induce a stable-bleb cell transformation (bottomleft), but cells can migrate only under confined conditions (bottom-right).

Movie S9. The endoplasmic reticulum (ER) is immobilized under the nucleus in deformed cells under high confinement (related to Fig. 7 and Suppl. Fig. 6). Time lapse TIRF movie of progenitor cells stained with ER tracker green under increasing mechanical confinement. At low mechanical confinement, the ER is mobile in the nucleus-plasma membrane contact area, while for increasing confinement the ER is immobilized in the region underneath the nucleus. The yellow line marks the nuclear area (visualized from bright field imaging). 


\section{Supplementary References}

80. A. Carreras-Sureda et al., ORMDL3 modulates store-operated calcium entry and lymphocyte activation. Human Molecular Genetics. 22, 519-530 (2013).

81. M. A. Breau et al., Extrinsic mechanical forces mediate retrograde axon extension in a developing neuronal circuit. Nat Commun. 8, 282-14 (2017).

82. M. R. Rebagliati, R. Toyama, P. Haffter, I. B. Dawid, cyclops encodes a nodal-related factor involved in midline signaling. PNAS. 95, 9932-9937 (1998).

83. Spatiotemporal dynamics of RhoA activity in migrating cells. Nature. 440, 1069-1072 (2006).

84. A. D. Edelstein et al., Advanced methods of microscope control using $\mu$ Manager software. Journal of biological methods. 1, 10 (2014).

85. A. Farré, F. Marsà, M. Montes-Usategui, Optimized back-focal-plane interferometry directly measures forces of optically trapped particles. Opt Express. 20, 12270-12291 (2012).

86. I. K. Mikhailyuk, A. P. Razzhivin, Background Subtraction in Experimental Data Arrays Illustrated by the Example of Raman Spectra and Fluorescent Gel Electrophoresis Patterns. Instruments and Experimental Techniques. 46, 765-769. 